\title{
p53-mediated redox control promotes liver regeneration and maintains liver function in response to $\mathrm{CCl}_{4}$
}

\author{
Timothy J. Humpton $\mathbb{D}^{1,2^{凶}}$, Holly Hall $\mathbb{D}^{2}{ }^{2}$, Christos Kiourtis ${ }^{2,3}$, Colin Nixon $\mathbb{D}^{2}$, William Clark $^{2}$, Ann Hedley ${ }^{2}$, Robin Shaw ${ }^{2}$, \\ Thomas G. Bird ${ }^{2,4}$, Karen Blyth ${ }^{2,3}$ and Karen H. Vousden (iD) ${ }^{1 \times}$ \\ (c) The Author(s) 2021
}

\begin{abstract}
The p53 transcription factor coordinates wide-ranging responses to stress that contribute to its function as a tumour suppressor. The responses to $\mathrm{p} 53$ induction are complex and range from mediating the elimination of stressed or damaged cells to promoting survival and repair. These activities of p53 can modulate tumour development but may also play a role in pathological responses to stress such as tissue damage and repair. Using a p53 reporter mouse, we have previously detected strong induction of p53 activity in the liver of mice treated with the hepatotoxin carbon tetrachloride $\left(\mathrm{CCl}_{4}\right)$. Here, we show that p53 functions to support repair and recovery from $\mathrm{CCl}_{4}$-mediated liver damage, control reactive oxygen species (ROS) and limit the development of hepatocellular carcinoma (HCC), in part through the activation of a detoxification cytochrome P450, CYP2A5 (CYP2A6 in humans). Our work demonstrates an important role for $\mathrm{p} 53$-mediated redox control in facilitating the hepatic regenerative response after damage and identifies CYP2A5/CYP2A6 as a mediator of this pathway with potential prognostic utility in human HCC.
\end{abstract}

Cell Death \& Differentiation (2022) 29:514-526; https://doi.org/10.1038/s41418-021-00871-3

\section{INTRODUCTION}

The TP53 ( $p 53$ ) transcription factor coordinates diverse aspects of the cellular stress response and is capable of engaging both prosurvival and pro-death pathways [1]. Although p53 was initially identified through its association with cancer, it also has broader roles in organismal health. p53 is required for efficient implantation of embryos into the uterus [2], promotes stamina during exercise [3, 4], limits fibrosis after chronic liver injury [5], and protects against Listeria monocytogenes infection [6]. Conversely, unrestrained activation of p53 in embryos is rapidly lethal [7-9], p53 promotes B-cell apoptosis in type 2 diabetes mellitus [10], and in ischaemia, inhibition of $\mathrm{p} 53$ is protective [11-13]. These disparate outcomes suggest a nuanced balance between divergent aspects of p53 activity.

The liver provides an excellent setting in which to examine the intersection of p53 signalling in cancer and normal biology. Disruption of TP53 is observed in 30-40\% of human hepatocellular carcinomas (HCCs) [14], suggesting tumour-suppressive functions for p53 in the liver. Indeed, the loss of hepatic p53 alone is sufficient to promote liver cancer in mice, albeit at long latency [15]. Even so, wild-type p53 is retained in more than half of human HCCs, with a previously identified TP53 gene expression signature characterising this group [14]. These observations suggest that aspects of p53 function may also support-or at least not directly antagonise-hepatic tumourigenesis.

Although the liver is largely quiescent in adults, it can undergo rapid regeneration after damage or resection [16]. As in HCC, the p53 pathway has been reported to support and antagonise liver regeneration. It has been shown that p53 limits liver damage after acetaminophen overdose and protects mitotic fidelity after partial hepatectomy, indicating protective roles for p53 in the hepatic injury response [17-19]. Similarly, p53-deficient mice exhibit enhanced sensitivity to high-dose irradiation during $\mathrm{CCl}_{4}$-induced regeneration [20]. In addition, the loss of CDKN1A/p21, a p53 target, has been reported to impair liver regeneration in certain liver damage models [21, 22]. However, robust activation of p21 has also been shown to promote senescence and to limit the regenerative response, and p21 loss can allow for survival after severe liver damage-suggesting that this arm of the p53 response may also impede liver regeneration [21, 23]. More directly, unrestrained activation of p53 is lethal in hepatocytes, p53-mediated apoptosis contributes to disease progression in a model of non-alcoholic steatohepatitis, and p53 activity promotes fibrosis in a model of chronic regeneration in rats [24-27]. Thus, the role of p53 in the hepatic response to toxic damage is not clear and may be dependent on the nature and severity of the initiating damage.

Here, we utilise $\mathrm{CCl}_{4}$-mediated liver regeneration as a model system to investigate the function of p53 in liver biology. Our work demonstrates a role for p53-mediated redox control in facilitating the hepatic regenerative response after damage. We identified CYP2A5/CYP2A6 as a mediator of this pathway with potential prognostic utility in human HCC.

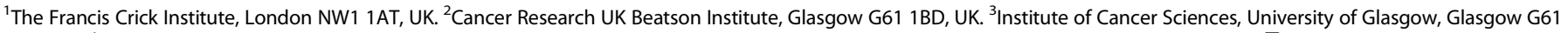

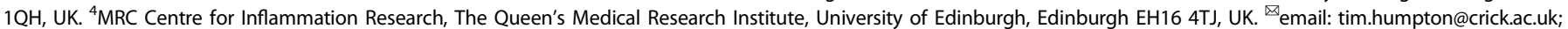
Karen.vousden@crick.ac.uk Edited by G. Melino
}

Received: 27 November 2020 Revised: 26 August 2021 Accepted: 7 September 2021 Published online: 9 October 2021 


\section{RESULTS}

Liver-specific loss of p53 exacerbates liver damage and increases ROS during $\mathrm{CCl}_{4}$-mediated liver regeneration

Using a p53 reporter mouse, we have previously detected strong induction of the p53 pathway, albeit without clear accumulation of p53 itself, in hepatocytes of mice treated with the hepatotoxin carbon tetrachloride $\left(\mathrm{CCl}_{4}\right)$. To explore the potential roles for $\mathrm{p} 53$ function during this process, we created mice harbouring liverspecific deletion of Trp53 (p53) (Albumin-Cre; p53 ${ }^{F L / F L}$ mice), confirmed that recombination of the $p 53$ floxed allele was highly efficient in the liver (Fig. S1A/B) and proceeded to characterise the acute response to $\mathrm{CCl}_{4}$-mediated liver toxicity using this model (Figs. 1A/B and S1 C-H). Importantly, mice of either $p 53$ genotype developed normally and were histologically indistinguishable prior to treatment (Fig. S1 C/D). Within the first $24 \mathrm{~h}$ following treatment with $\mathrm{CCl}_{4}$, Albumin-Cre; p53 ${ }^{\text {WT } / W T}$ mice (p53 WT) mice exhibited evident liver damage, including vacuolisation, neutrophil infiltration, and destruction of Glutamine Synthetase (GS)positive peri-central vein hepatocytes (Figs. $1 \mathrm{~A} / \mathrm{B}$ and $\mathrm{S} 1 \mathrm{C}-\mathrm{H}$ ). Damage progressed outward from the central vein over the first 48-72 hours after treatment before resolving within the remainder of the 168-h time-course (Figs. 1A/B and S1 C/D). In Albumin-Cre; $p 53^{F L / F L}$ mice, although GS-positive hepatocyte destruction and damage-associated neutrophil infiltration were similar to p53 WT mice (Fig. S1E-H), liver damage progressed outward from the pericentral vein region more rapidly, coalescing into larger regions of injury at $24 \mathrm{~h}$ after $\mathrm{CCl}_{4}$ treatment (Figs. $1 \mathrm{~A} / \mathrm{B}$ and $\mathrm{S} 1 \mathrm{C} / \mathrm{D}$ ). Even so, the liver damage in Albumin-Cre; $p 53^{F L / F L}$ mice also resolved within $168 \mathrm{~h}$.

To confirm our histological assessment of liver damage, we examined the presence of alanine and aspartate transaminase (ALT/AST) activity in blood plasma, two markers of liver damage. In agreement with the liver histology, we noted extended elevation of plasma ALT and AST activity in Albumin-Cre; $p 53^{F L / F L}$ mice (Fig. 1C/D), suggesting elevated liver damage in these mice. Even so, as observed in liver histology, plasma ALT and AST levels ultimately normalised by $168 \mathrm{~h}$ after treatment in mice of both genotypes, suggesting potentially significant but transient effects of p53 during $\mathrm{CCl}_{4}$-mediated liver regeneration. These findings are consistent with previous reports of p53 acting to limit liver damage after acetaminophen overdose [18, 19], where p53 exerted short-lived protective effects.

One of the features of damage-mediated liver regeneration is the dramatic but transient microvesicular steatosis that occurs prior to initiation of the proliferative phase of the regenerative response [28-30]. The resulting accumulation of lipids can be visualised as red puncta in oil-red O-stained liver sections. In contrast to our liver damage assessments, we observed a similar peak accumulation of oil-red-O staining at $24 \mathrm{~h}$ after $\mathrm{CCl}_{4}$ treatment in the livers of Albumin-Cre; $p 53^{\mathrm{WT} / \mathrm{WT}}$ and AlbuminCre; $p 53^{F L / F L}$ mice (Fig. 1E/F). However, while lipid levels rapidly normalised by $48 \mathrm{~h}$ after treatment in Albumin-Cre; $p 53^{\mathrm{WT} / \mathrm{WT}}$ mice, elevated oil-red-O staining persisted in Albumin-Cre; $p 53^{F L / F L}$ mice for an additional 2 days (Fig. 1E/F).

The initial reductive dehalogenation of $\mathrm{CCl}_{4}$ generates shortlived but highly reactive intermediates that potently oxidise lipids and cause DNA damage [31,32]. Peroxidized lipids can impede mitochondrial function, including fatty acid oxidation, and impair lipid export-potentially contributing to lipid accumulation during $\mathrm{CCl}_{4}$ detoxification [33-35]. Considering the established role for p53 supporting the redox response [36], we investigated whether the disrupted lipid clearance in Albumin-Cre; $p 53^{F L F L}$ mice was a consequence of decreased ROS detoxification. Indeed, levels of malondialdehyde (MDA), a marker of lipid peroxidation, were elevated to a greater extent, and for an additional two days, in Albumin-Cre; $p 53^{F L / F L}$ mice compared with Albumin-Cre; $p 53^{W T / W T}$ mice (Fig. 1G/H).
To investigate the contribution of ROS stress to deficiencies in liver regeneration in Albumin-Cre; $p 53^{F L / F L}$ mice, we compared $\mathrm{CCl}_{4^{-}}$ mediated regeneration between Albumin-Cre; $p 53^{F L / F L}$ mice given normal drinking water to those provided with $\mathrm{N}$-Acetylcysteine (NAC)-supplemented drinking water. NAC treatment is an established antidote to liver toxicity that results from acetaminophen overdose in humans and functions by maintaining liver glutathione levels during the detoxification process [37]. As expected, NAC treatment significantly attenuated lipid peroxidation in AlbuminCre; $p 53^{F L / F L}$ mice (Fig. 1I/J). NAC treatment also promoted significantly more rapid clearance of lipid droplets (Fig. 1K/L), suggesting that redox management is an important feature of the p53-mediated response to hepatic $\mathrm{CCl}_{4}$ toxicity.

\section{Liver p53 engages Cyp2a5/CYP2A6 to support redox control} during $\mathrm{CCl}_{4}$-mediated liver regeneration

Given the differences in redox control between Albumin-Cre; $p 53^{W T / W T}$ and Albumin-Cre; p53 $3^{F L / F L}$ mice at $24 \mathrm{~h}$ after $\mathrm{CCl}_{4}$ treatment, we focused on the early response to toxicity. At $8 \mathrm{~h}$ after $\mathrm{CCl}_{4}$ treatment, we observed similar oil-red-O staining to baseline and comparable lipid peroxidation between livers taken from Albumin-Cre; $p 53^{W T / W T}$ and Albumin-Cre; $p 53^{F L / F L}$ mice (Fig. 2A/B), suggesting that bifurcation of the regenerative response had not yet occurred. Bulk RNA-seq analysis at this time point identified 13 significant differentially regulated genes between Albumin-Cre; $p 53^{\text {WT/WT }}$ and Albumin-Cre; $p 53^{\text {FL/FL }}$ livers 8 $\mathrm{h}$ after $\mathrm{CCl}_{4}$ treatment (Fig. S2A). Clustering analysis stratified these genes into three groups, one of which contained p53 itself and four established p53 targets: Cong1/Cyclin G1, Eda2r, Zmat3/ Wig-1, and Abcb1a/Mdr1 [38-41] (Fig. 2C). Our attention was drawn to the remaining member of this cluster, Cyp2a5, encoding a cytochrome P450 enzyme that is induced by NFE2L2 (NRF2) to aid in the murine redox response during ethanol detoxification $[42,43]$. CYP2A6, the human orthologue of Cyp2a5 [44], has been shown to be a transcriptional target of p53 [45], suggesting potential p53-directed functions for Cyp2a5 in the mouse as well.

Consistent with our RNA-seq data, we confirmed that expression of Cyp2a5 was induced in Albumin-Cre; $p 53^{W T / W T}$ mice within the first 8-24 $\mathrm{h}$ after $\mathrm{CCl}_{4}$ treatment, with later induction observed in Albumin-Cre; $p 53^{F L / F L}$ mice alongside increased levels of the NRF2 target gene Nqo1 (Fig. S2B/C). Through IHC staining, we confirmed higher levels of CYP2A5 protein in livers of Albumin-Cre; $p 53^{W T / W T}$ compared to Albumin-Cre; $p 53^{F L / F L}$ mice within $24 \mathrm{~h}$ after $\mathrm{CCl}_{4}$ treatment as well (Fig. 2D/E). CYP2A5 levels remained significantly elevated in Albumin-Cre; p53 ${ }^{\text {WT/WT }}$ livers at 48 and $72 \mathrm{~h}$ after treatment, with a delayed increase evident in AlbuminCre; $p 53^{F L / F L}$ livers at $48-72 \mathrm{~h}$ after $\mathrm{CCl}_{4}$ treatment (Fig. 2D/E).

Interestingly, although we observed potent early induction of the p53 target gene Cdkn1a/p21 in Albumin-Cre; p53 5 WTWT mice, this was matched by similar induction in Albumin-Cre; $p 53^{F L / F L}$ mice, a finding that we confirmed by IHC staining for $\mathrm{p} 21$ at $8 \mathrm{~h}$ after $\mathrm{CCl}_{4}$ treatment (Fig. S2D/E). These findings suggest that early expression of p21 after $\mathrm{CCl}_{4}$ treatment is p53-independent (Fig. S2D/E), in contrast to its p53-dependent induction later in the regenerative process (Fig. S2D). These results also explain why Cdkn1a was not differentially expressed in our RNA-seq analysis. Expression of CYP2A5, in contrast, was elevated in Albumin-Cre; $p 53^{W T / W T}$ mice but significantly lower in Albumin-Cre; $p 53^{F L / F L}$ livers at this time point, consistent with our RNA-seq data (Fig. S2F). Bbc3/Puma, a pro-apoptotic p53 target gene that has been shown to play a role in modulating liver metabolism in human HCC [46], was not differentially expressed between Albumin-Cre; $p 53^{\text {WT } W T}$ and Albumin-Cre; $p 53^{F L / F L}$ mice during $\mathrm{CCl}_{4}$-mediated regeneration (Fig. S2G), reinforcing the idea that not all aspects of p53 activity are engaged during liver regeneration.

In the Mdm2 $2^{E \times 5 / 6 \Delta}$ mouse model, excision of $M d m 2$ exons 5 and $6\left(M d m 2^{E \times 5 / 6 \Delta}\right)$, comprising the p53-binding domain of MDM2, 
A

Time post- $\mathrm{CCl}_{4}$ (hrs)

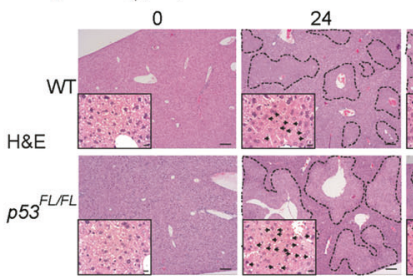

C

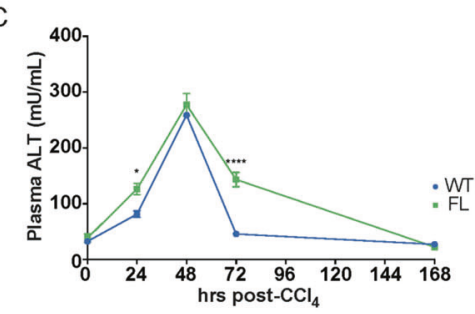

E Time post-CCl ${ }_{4}$ (hrs)

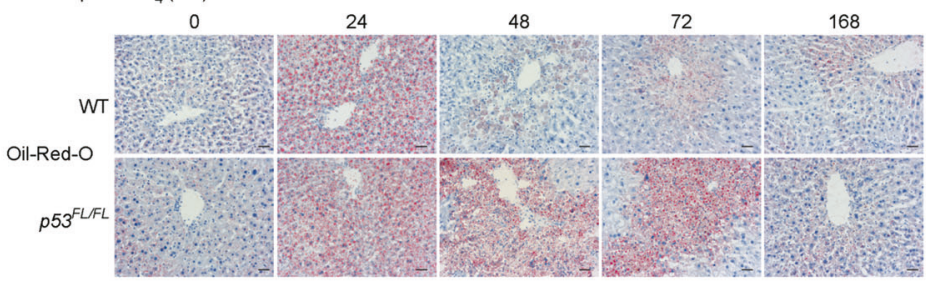

G

Time post- $\mathrm{CCl}_{4}(\mathrm{hrs})$

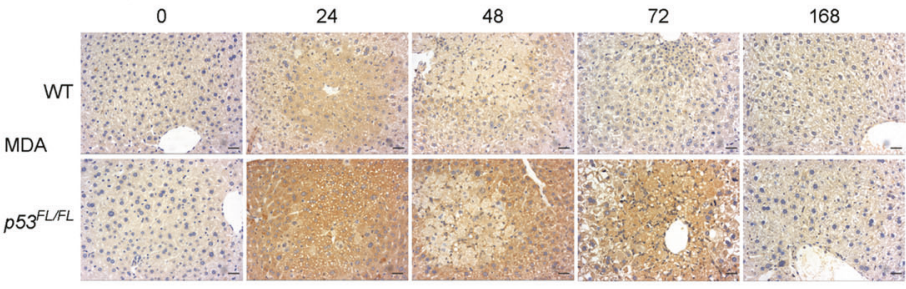

I Time post- $-\mathrm{CCl}_{4}$ (hrs)

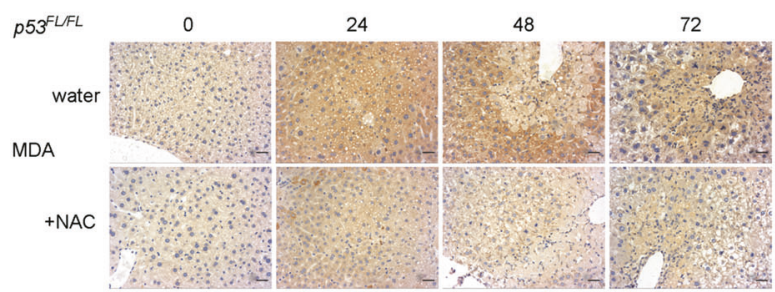

K

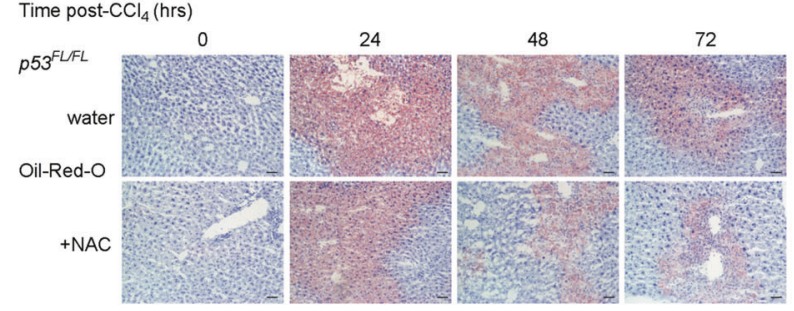

B
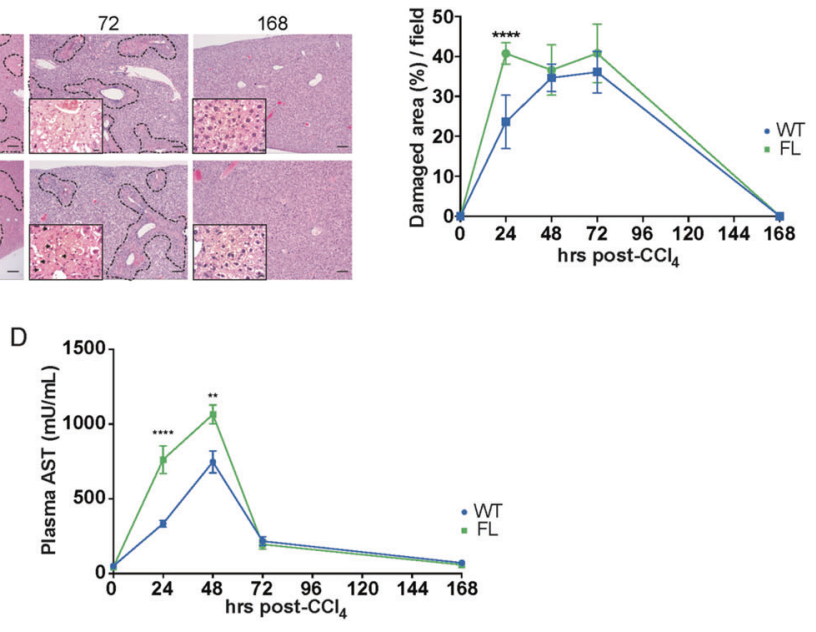

F

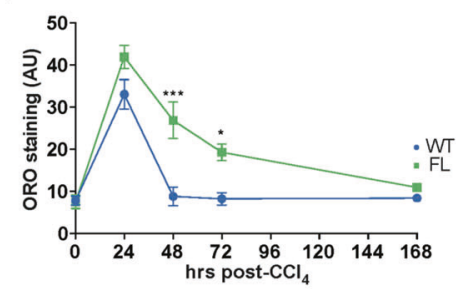

$\mathrm{H}$

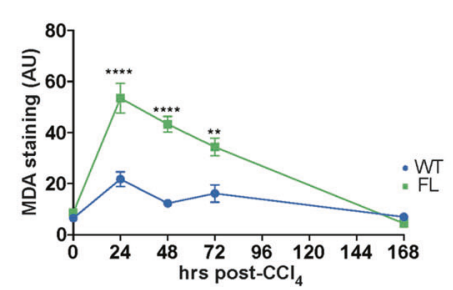

$J$

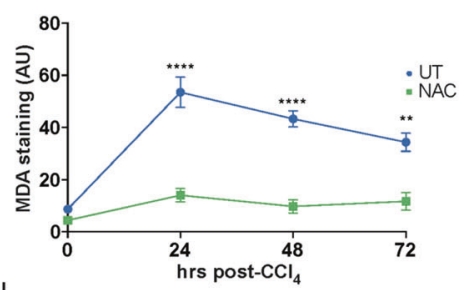

L

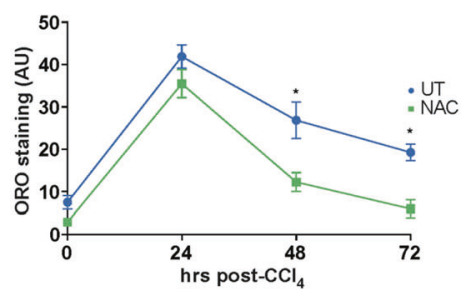

leads to rapid stabilisation of p53, robust expression of p53 target genes, and ultimately in p53-dependent lethality within 4-5 days $[24,47]$. RNA-seq analysis of mice sampled at two days after treatment with liver-specific AAV8-TBG-Cre [48] to induce expression of $M d m 2^{E \times 5 / 6 \Delta}$, a time point before widespread liver attrition, confirmed significant induction of Cyp2a5. Indeed, we identified all of the genes in our $\mathrm{CCl}_{4}$ RNA-seq analysis, alongside classical p53 targets such as p21 and Puma in this alternative model (Fig. $\mathrm{S} 2 \mathrm{H}$ ). As in the $\mathrm{CCl}_{4}$ liver regeneration model, we validated the induction of p21 and CYP2A5, as well as stabilisation of p53, via IHC (Fig. S2I-K). Combined, these findings confirm that activation of p53 engages CYP2A5 in the liver. 
Fig. 1 Loss of liver p53 exacerbates liver damage and increases ROS during CCl4-mediated liver regeneration. Representative H\&E images (A) and quantification (B) of damaged area (\% per field) in livers from Albumin-Cre; $p 53^{\mathrm{WT} / \mathrm{WT}}$ mice (WT) and Albumin-Cre; $p 53^{\mathrm{FL} / \mathrm{FL}}$ (FL) mice at indicated times (hours) following $\mathrm{CCl}_{4}$ treatment. Damaged areas outlined. Scale bars $100 \mu \mathrm{m}$. Higher magnification inset images highlight centrilobular liver damage including vacuolisation (black arrows). These images are taken from different H\&E slides than those depicted for damaged area. Scale bars $10 \mu \mathrm{m}$. Images reproduced without annotation and at full size in Fig. S1 C/D. Quantifications from $N=2$ untreated ( 0 h) mice/group, $N=6$ mice/group at $24 \mathrm{~h}, N=5 \mathrm{WT}$ and $N=4 \mathrm{FL}$ mice at $48 \mathrm{~h}, N=7$ mice/group at $72 \mathrm{~h}, \mathrm{~N}=3 \mathrm{mice} / \mathrm{group}$ at $168 \mathrm{~h}$. Data presented as mean \pm SEM and analysed using two-way ANOVA with Holm-Sidak's multiple comparisons test and multiplicity-adjusted $p$ values. ${ }_{* * * *}<<0.0001$. Plasma ALT (C) and AST (D) activity (mU/mL) in Albumin-Cre; $p 53^{W T W T}$ (WT) and Albumin-Cre; $p 53^{F L / F L}$ (FL) mice treated as in (A). $N=3$ untreated $(0 \mathrm{~h})$ mice/group. $N=4$ mice/group/time point thereafter. Each data point represents the mean from technical duplicates per mouse. Data presented as mean \pm SEM and analysed using two-way ANOVA with Holm-Sidak's multiple comparisons test and multiplicityadjusted p-values. ${ }^{*} p<0.05,{ }^{* *} \mathrm{p}<0.01,{ }^{* * * *} p<0.0001$. Staining $(\mathbf{E})$ and quantification of stain area (F) of frozen sections for oil-red-O (ORO) in Albumin-Cre; $p 53^{W T} / W T$ (WT) and Albumin-Cre; $p 53^{F L / F L}(\mathrm{FL})$ mice treated as in (A). Scale bars $20 \mu \mathrm{m}$. Quantification from $N=5$ untreated $(0 \mathrm{~h}), 24$ $\mathrm{h}$, and $48 \mathrm{~h}$ mice/group, $N=7$ mice/group at $72 \mathrm{~h}$, and $\mathrm{N}=3 \mathrm{mice} / \mathrm{group}$ at $168 \mathrm{~h}$. Data presented as mean $\pm \mathrm{SEM}$ and analysed using two-way ANOVA with Holm-Sidak's multiple comparisons test and multiplicity-adjusted $p$ values. ${ }^{*} p<0.05$, ${ }^{* * *} p<0.001$. Data from $p 53^{F L / F L}$ mice also used in (L) (normal water) but different representative images are shown. IHC staining (G) and quantification (H) of malondialdehyde (MDA) in Albumin-Cre; $p 53^{W T / W T}$ (WT) and Albumin-Cre; $p 53^{F L / F L}$ (FL) mice at indicated times (hours) after $\mathrm{CCl}_{4}$ treatment. Scale bars $20 \mu \mathrm{m}$. Quantification from $N=6$ untreated $(0 \mathrm{~h})$ mice/group, $N=7 \mathrm{WT}$ and $\mathrm{N}=6 \mathrm{FL}$ mice at $24 \mathrm{~h}, \mathrm{~N}=7$ mice/group at 48 and $72 \mathrm{~h}$, and $\mathrm{N}=3 \mathrm{mice} / \mathrm{group}$ at $168 \mathrm{~h}$. Data presented as mean \pm SEM and analysed using two-way ANOVA with Holm-Sidak's multiple comparisons test and multiplicity-adjusted $p$ values. ${ }^{* *} p<0.01,{ }^{* * * *} p<0.0001$. Data from $p 53^{F L F L}$ mice also used in (J) (normal water) but different representative images are shown. IHC staining (I) and quantification (J) of malondialdehyde (MDA) in Albumin-Cre; $p 53^{F L / F L}$ (FL) mice given control (water) or $30 \mathrm{mM} \mathrm{N}$-Acetylcysteinesupplemented drinking water (NAC) for one week prior to $\mathrm{CCl}_{4}$ treatment. Images from indicated times (hours) after $\mathrm{CCl}_{4}$ treatment. Scale bars $20 \mu \mathrm{m}$. Quantification from $N=6$ water and $N=2$ NAC untreated mice $(0 \mathrm{~h}), N=6$ water and $N=4 \mathrm{NAC}$ mice at $24 \mathrm{~h}, N=7 \mathrm{water}$ and $N=4$ NAC mice at 48-72 h. Data presented as mean \pm SEM and analysed using two-way ANOVA with Holm-Sidak's multiple comparisons test and multiplicity-adjusted p-values. ${ }^{* *} p<0.01,{ }^{* * * *} p<0.0001$. Data from $p 53^{F L / F L}$ (normal water) mice also used in (H) but different representative images are shown. Staining (K) and quantification (L) of oil-red-O (ORO) in Albumin-Cre; p53 $3^{F L F L}$ (FL) mice given control (water) or $30 \mathrm{mM} \mathrm{N}$ Acetylcysteine-supplemented drinking water (NAC) for one week prior to $\mathrm{CCl}_{4}$ treatment. Images from indicated times (hours) after $\mathrm{CCl}_{4}$ treatment. Scale bars $20 \mu \mathrm{m}$. Quantification from $N=5$ untreated water $(0 \mathrm{~h})$ and $N=2$ untreated NAC mice, $N=5$ water and $N=4$ NAC mice at 24 and $48 \mathrm{~h}, N=7$ water and $N=4$ NAC mice at $72 \mathrm{~h}$. Data presented as mean \pm SEM and analysed using two-way ANOVA with Holm-Sidak's multiple comparisons test and multiplicity-adjusted $p$-values. ${ }^{*} p<0.05$. Data from $p 53^{F L / F L}$ (normal water) mice also used in (F) but different representative images are shown.

To explore the role of CYP2A5/CYP2A6 in damaged hepatocytes more fully in vitro, we turned to HepG2 and SK-Hep-1 cells, human HCC cell lines that maintain wild type p53 [46] (Fig. 2F/G). Treatment of these cells with Nutlin, a direct activator of p53 [49], induced expression of $C D K N 1 A / p 21$, as expected, as well as CYP2A6. Treatment of both HepG2 and SK-Hep-1 cells with $\mathrm{CCl}_{4}$ also induced $p 21$ and CYP2A6 expression (Fig. $2 \mathrm{~F} / \mathrm{G}$ ). This response was abrogated following siRNA-mediated depletion of TP53, confirming the role of $\mathrm{p} 53$ in the upregulation of $p 21$ and CYP2A6 expression in response to $\mathrm{CCl}_{4}$ in vitro (Fig. $2 \mathrm{~F} / \mathrm{G}$ ).

Functionally, both HepG2 and SK-Hep-1 cells treated with $\mathrm{CCl}_{4}$ exhibited increased ROS levels, and this was exacerbated in CYP2A6-depleted cells (Fig. 2H/l). Treatment of HepG2 and SKHep-1 cells with cumene hydroperoxide $(\mathrm{CH})$, a stable organic oxidising agent [50], similarly engaged CYP2A6 and CDKN1A/p21 (Fig. S2 L/M), and CYP2A6-depletion also increased cellular ROS levels after $\mathrm{CH}$ treatment (Fig. $2 \mathrm{~J} / \mathrm{K}$ ) - suggesting that downstream $\mathrm{ROS}$, rather than $\mathrm{CCl}_{4}$ directly, promotes activation of CYP2A6 to aid in ROS detoxification. Interestingly, although induction of CYP2A6 was p53-dependent in response to $\mathrm{CCl}_{4}$ treatment, CYP2A6 increased independently of p53 after $\mathrm{CH}$ treatment (Fig. S2L/M). Since hydroperoxides have been shown to activate NRF2 in HepG2 cells [51], this finding is consistent with an established role for NRF2-induced Cyp2a5 supporting the redox response during ethanol detoxification in mice $[42,43]$. Based on these findings, we concluded that the p53-dependent activation of CYP2A5 in response to $\mathrm{CCl}_{4}$ treatment in vivo contributed to the enhanced detoxification of lipid ROS in support of rapid regeneration in Albumin-Cre; $p 53^{W T / W T}$ mice.

\footnotetext{
Hepatocyte p53 protects liver function and limits tumourigenesis following $\mathrm{CCl}_{4}$-mediated chronic regeneration A close relationship has been described between chronic regeneration and cancer-with tumourigenesis sometimes conceptualised as 'a wound that does not heal' [52]. While we detected clear defects in redox control and liver function during one round of $\mathrm{CCl}_{4}$ treatment and regeneration in Albumin-Cre; $p 53^{F L / F L}$ mice compared to Albumin-Cre; $p 53^{W T / W T}$ mice, these
}

differences were transient and resolved within one week (Fig. 1). In contrast to acute damage, repeated regeneration resulting from regular $\mathrm{CCl}_{4}$ treatment causes lasting fibrotic liver damage, leading to cirrhosis and HCC $[53,54]$. This progression is exacerbated by systemic DNA damage, chronic inflammation, and ROS stress $[55,56]$. With these findings in mind, we investigated the effects of lack of liver p53 on fibrosis and HCC development in the wellestablished $\mathrm{CCl}_{4}$ chronic liver regeneration model [5] (Fig. S3A).

One week after the conclusion of the 10-week chronic regeneration regime, we observed striking generalised hepatocyte hypertrophy [57] throughout the livers of Albumin-Cre; $p 53^{F L / F L}$ mice that was absent in similarly treated Albumin-Cre; $p 53^{\text {WT }}$ WT mice (Fig. 3A/B). In hepatic stellate cells (HSCs), p53 has been shown to limit fibrosis after chronic regeneration in the liver [5]. However, we found that hepatocyte-specific p53 loss did not lead to differences in activated HSC content, as evaluated by IHC staining for alpha-smooth muscle actin (aSMA), or to increased fibrosis as assessed by picrosirius red staining (PSR) (Fig. 3B-D). In fact, we observed a modest decrease in fibrosis in Albumin-Cre; $p 53^{F L / F L}$ mice (Fig. 3B/D), consistent with a previous report showing that hepatocyte p53 can enhance fibrosis during $\mathrm{CCl}_{4^{-}}$ mediated chronic regeneration in rats [27]. Although murine hepatocyte p53 does not appear to limit fibrosis after chronic regeneration either, we nevertheless detected higher levels of unresolved DNA damage, measured by IHC staining for phosphohistone $\mathrm{H} 2 \mathrm{~A} . \mathrm{X}(\mathrm{gH} 2 \mathrm{AX})$, increased lipid peroxidation (measured by MDA) and-as expected-decreased levels of CYP2A5 in livers from Albumin-Cre; $p 53^{F L / F L}$ mice (Fig. 3E/F). Functionally, we also found that plasma levels of ALT and AST enzyme activity were both elevated in Albumin-Cre; $553^{F L / F L}$ mice after chronic regeneration, consistent with compromised liver function in these mice (Fig. 3G).

In wild-type mice, it can take up to 2 years for HCC to arise from chronic $\mathrm{CCl}_{4}$ treatment [58]. Consistent with this, few Albumin-Cre; $p 53^{W T / W T}$ mice $(3 / 14)$ reached clinical endpoint within 550 days after initial $\mathrm{CCl}_{4}$ treatment in our experimental cohorts (Fig. 4A). In contrast, Albumin-Cre; $p 53^{F L / F L}$ mice exhibited accelerated and highly penetrant development of liver tumours in this timeframe 
A

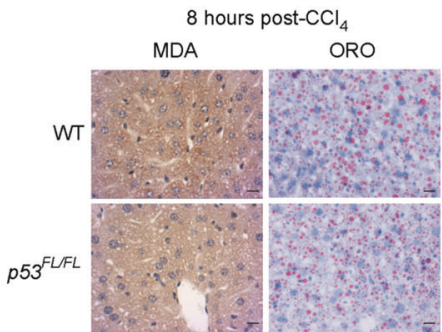

B

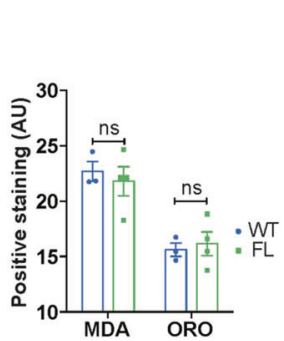

C

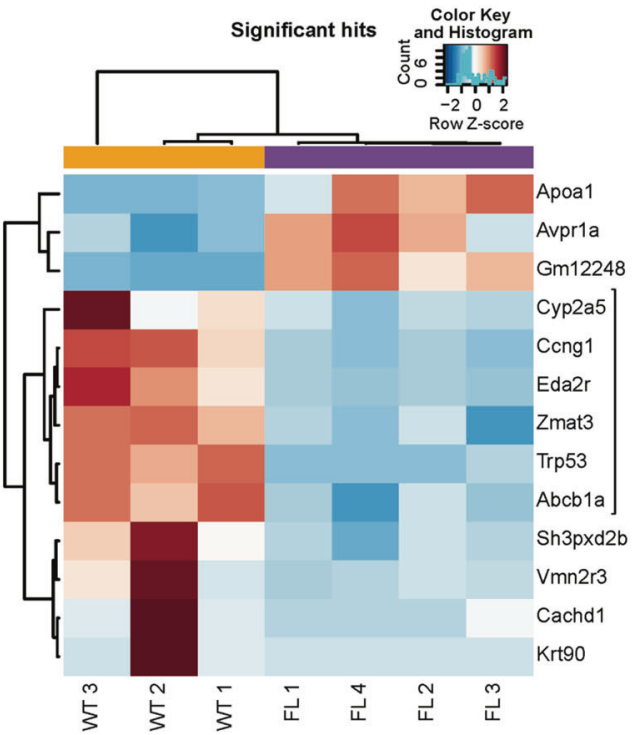

G

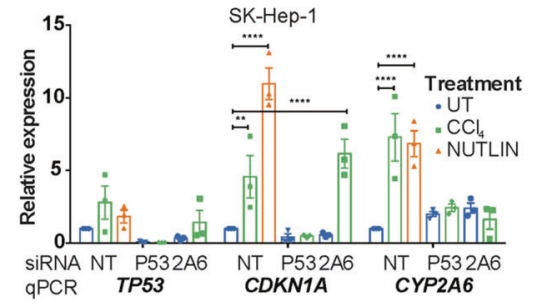

F

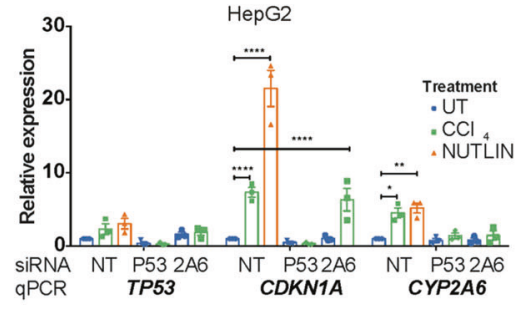

H

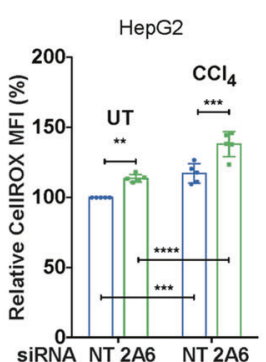

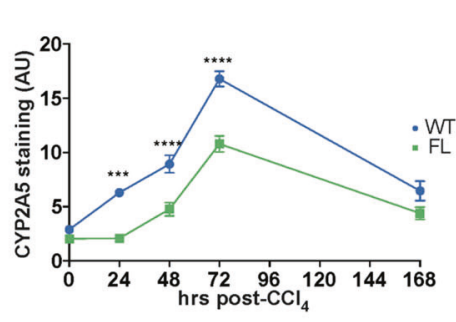

I

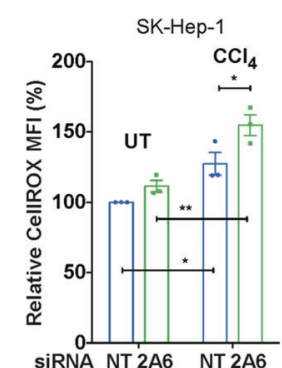

J

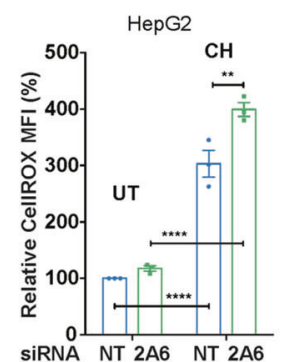

K

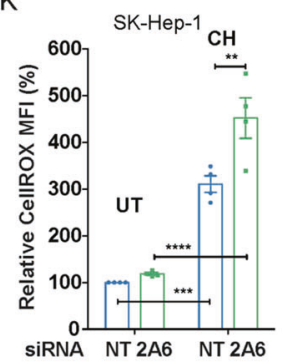

Fig. 2 Liver p53 engages Cyp2a5/CYP2A6 to support redox control during CCl4-mediated liver regeneration. Staining (A) and quantification (B) for malondialdehyde (MDA) and oil-red-O (ORO) in Albumin-Cre; $p 53^{\text {WT/WT }}$ (WT) and Albumin-Cre; $p 53^{F L / F L}$ (FL) mice at $8 \mathrm{~h}$ after $\mathrm{CCl}_{4}$ treatment. Scale bars $10 \mu \mathrm{m}$. Representative of $\mathrm{N}=3 \mathrm{WT}$ and $\mathrm{N}=4 \mathrm{FL}$ mice. Data presented as mean \pm SEM and analysed using two-tailed t-tests and the Sidak-Bonferroni method to account for multiplicity of tests. ns not significant. C Clustering analysis of significant differentially expressed genes (adjusted $p<0.05$ ) from RNA-seq analysis between Albumin-Cre; $p 53^{W T W T}$ (WT) and Albumin-Cre; $p 53^{F L / F L}$ (FL) mice at $8 \mathrm{~h}$ after $\mathrm{CCl}_{4}$ treatment. Samples from $\mathrm{N}=3 \mathrm{WT}$ and $\mathrm{N}=4 \mathrm{FL}$ mice included in analysis. Positive $Z$-score values correspond to genes enriched in livers of mice of the genotype indicated in the sample name. Cyp2a5-associated cluster as indicated. For further information, see materials and methods. IHC staining (D) and quantification (E) of CYP2A 5 in Albumin-Cre; $p 53^{\text {WT }}{ }^{\text {(WT }}$ (WT) and Albumin-Cre; $p 53^{F L / F L}$ (FL) mice at indicated times (hours) after $\mathrm{CCl}_{4}$ treatment. Scale bars $20 \mu \mathrm{m}$. Quantification from $N=4$ untreated $(0 \mathrm{~h})$ mice/group, $N=5 \mathrm{mice} / \mathrm{group}$ at $24 \mathrm{~h}, N=7 \mathrm{mice} /$ group at 48 and $72 \mathrm{~h}$, and $N=3$ mice/group at $168 \mathrm{~h}$. Data presented as mean \pm SEM and analysed using two-way ANOVA with Holm-Sidak's multiple comparisons test and multiplicity-adjusted $p$ values. ${ }^{* *} p<0.001,{ }^{* * * *} p<0.0001$. RT-qPCR analysis of expression of TP53, CDKN1A and CYP2A6 relative to ACTIN in HepG2 (F) and SK-Hep-1 (G) cells treated with siRNA against TP53, CYP2A6 (2A6), or non-targeting control (NT) $96 \mathrm{~h}$ prior to analysis and additionally treated with either DMSO control (UT), $C \mathrm{Cl}_{4}(4 \mathrm{mM})$, or with Nutlin $(10 \mu \mathrm{M})$ for $24 \mathrm{~h}$ prior to analysis. $N=3$ independent samples/condition. Data presented as mean \pm SEM and analysed using two-way ANOVA with Holm-Sidak's multiple comparisons test and multiplicity-adjusted $p$ values. ${ }^{*} p<0.05,{ }^{* *} p<0.01,{ }^{* * * *} p<0.0001$. Measurement of cellular ROS levels relative to baseline using the CellROX fluorescent probe in HepG2 (H) and SK-Hep-1 (I) cells treated with non-targeting control (NT) or CYP2A6 (2A6) siRNA for 96 hours and additionally treated with either DMSO control (UT) or with $\mathrm{CCl}_{4}(4 \mathrm{mM})$ in DMSO for $24 \mathrm{~h}$ prior to analysis. $\mathrm{N}=5$ independent HepG2 and $\mathrm{N}=$ 3 SK-Hep-1 samples/condition. Data presented as median fluorescent intensity (MFI) \pm SEM relative to untreated NT cells and analysed using two-way ANOVA with Holm-Sidak's multiple comparisons test and multiplicity-adjusted $p$ values. ${ }^{*} p<0.05,{ }^{* *} p<0.01,{ }^{* * *} p<0.001,{ }^{* * * *} p<$ 0.0001 . Measurement of cellular ROS levels relative to baseline using the CellROX fluorescent probe in HepG2 (J) or SK-Hep-1 cells (K) treated with non-targeting control (NT) or CYP2A6 (2A6) siRNA for $96 \mathrm{~h}$ and additionally treated with either DMSO control (UT) or with cumene hydroperoxide $(10 \mu \mathrm{M})(\mathrm{CH})$ for $24 \mathrm{~h}$ prior to analysis. $N=3$ independent samples/condition in HepG2 cells and $N=4 /$ condition in SK-Hep-1 cells. Data presented as median fluorescent intensity (MFI) \pm SEM relative to untreated NT cells and analysed using two-way ANOVA with Holm-Sidak's multiple comparisons test and multiplicity-adjusted $p$ values. ${ }^{* *} p<0.01,{ }^{* * *} p<0.001,{ }^{* * * *} p<0.0001$. 
Liver tissue 7 days after conclusion of chronic $\mathrm{CCl}_{4}$ dosing regime

A

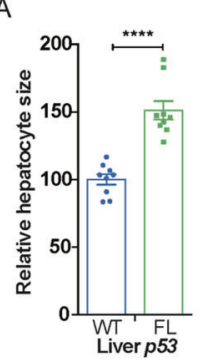

$\mathrm{B}$

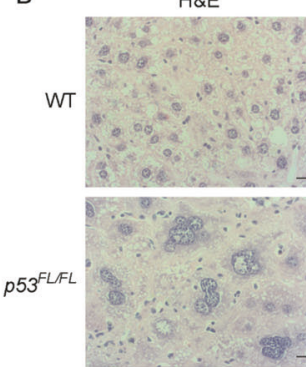

aSMA

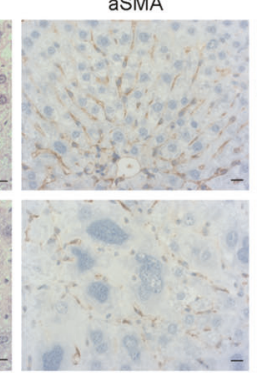

PSR

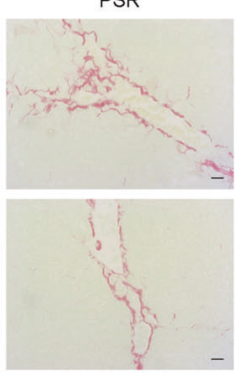

F
C

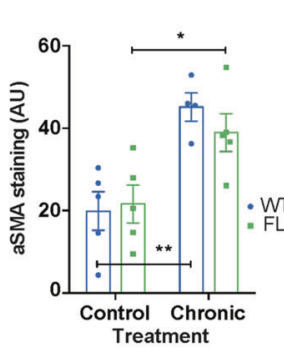

D

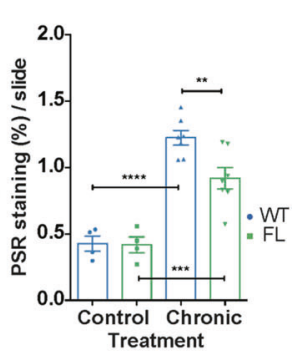

E

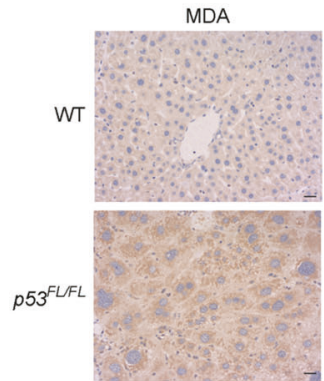

CYP2A5

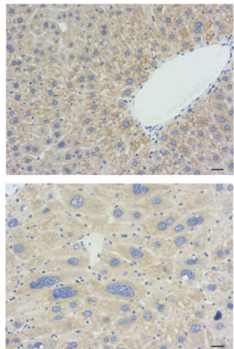

$\mathrm{gH} 2 \mathrm{AX}$

G
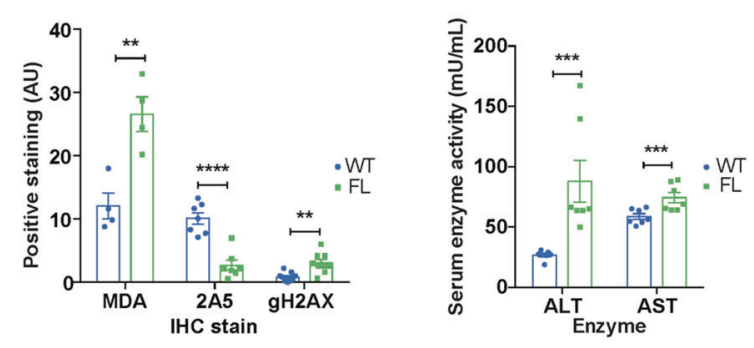

Fig. 3 Loss of liver p53 leads to hepatic hypertrophy, chronic ROS and DNA damage, and impaired liver function after CCI4-mediated chronic regeneration. A Quantification of relative hepatocyte size in Albumin-Cre; $p 53^{W T W T T}$ (WT) and Albumin-Cre; $p 53^{F L / F L}$ (FL) mice at 7 days after completion of 10 -week $\mathrm{CCl}_{4}$ chronic regeneration regime. $N=9$ mice/genotype. Data presented as mean $\pm \mathrm{SEM}$ and analysed using an unpaired two-tailed $t$-test with Welch's correction. ${ }^{* *} p<0.01$. B H\&E and IHC staining for alpha-smooth muscle actin (aSMA), and picrosirius red (PSR) staining in Albumin-Cre; $p 53^{W T / W T}$ (WT) and Albumin-Cre; $p 53^{F L / F L}$ (FL) mice at 7 days after completion of $10-$-week CCl ${ }_{4}$ chronic regeneration regime. Scale bars $10 \mu \mathrm{m}$. Images representative of $N=10 \mathrm{WT}$ and $N=8 \mathrm{FL}$ mice for H\&E, $N=4 \mathrm{WT}$ and $N=5 \mathrm{FL}$ mice for aSMA, and $N=7$ mice/group for PSR. C Quantification of IHC staining for aSMA in Albumin-Cre; $p 53^{W T / W T}$ (WT) and Albumin-Cre; $p 53^{F L / F L}$ (FL) mice from (B) at either 7 days after completion of 10 -week $\mathrm{CCl}_{4}$ chronic regeneration regime (chronic) or in untreated age-matched mice (control). $N=5$ control mice/genotype, $N=4$ WT and $N=5$ FL chronic mice. Data presented as mean \pm SEM and analysed using two-way ANOVA with Holm-Sidak's multiple comparisons test and multiplicity-adjusted $p$ values. ${ }^{* *} p<0.01$. D Quantification of staining for picrosirius red (PSR) in Albumin-Cre; $p 53^{W T W T}$ (WT) and Albumin-Cre; $p 53^{F L F L}$ (FL) mice as in (C). $N=4$ control mice/genotype and $N=7$ chronic $C \mathrm{Cl}_{4}$ mice/genotype. Data presented as mean \pm SEM and analysed using two-way ANOVA with Holm-Sidak's multiple comparisons test and multiplicity-adjusted $p$ values. ${ }^{* *} p<0.01,{ }^{* * *} p<0.001,{ }^{* * * *} p<0.0001$. Images (E) and quantification (F) of IHC staining MDA, CYP2A5, and gH2AX in Albumin-Cre; $p 53^{W T W T}$ (WT) and Albumin-Cre; $p 53^{F L / F L}$ (FL) mice at 7 days after completion of 10 -week $\mathrm{CCl}_{4}$ chronic regeneration regime as in (C). Scale bars $20 \mu \mathrm{m}$. $N=4$ mice/group for MDA, $N=7$ mice/group for CYP2A5, and $N=9$ mice/group for gH2AX. Data presented as mean \pm SEM and analysed using two-tailed $t$-tests and the Sidak-Bonferroni method to account for multiplicity of tests. ${ }^{* *} p<0.01,{ }^{* * * *} p<0.0001$. G Plasma ALT

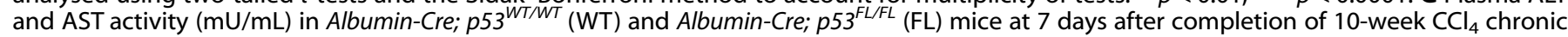
regeneration regime. $N=7$ mice/group. Each data point represents the mean from technical duplicates per mouse. Data presented as mean \pm SEM and analysed using two-tailed $t$-tests and the Sidak-Bonferroni method to account for multiplicity of tests. ${ }^{* *} p<0.001$.

(9/9 mice, median survival 380 days after first $\mathrm{CCl}_{4}$ treatment) (Fig. 4A). Most mice of both genotypes (2/3 Albumin-Cre; p53 5 WT/WT mice and $5 / 9$ Albumin-Cre; $p 53^{F L / F L}$ mice) reaching clinical endpoint exhibited large tumour lesions but also retained nontumour (normal-like) tissue (Fig. S3B). These regions were sampled as 'tumour' and 'non-tumour' tissue for subsequent analyses. At the experiment endpoint (550 days after initial treatment), most $\mathrm{CCl}_{4}$-treated Albumin-Cre; $p 53^{W T / W T}$ mice $(11 / 14)$, all untreated Albumin-Cre; $p 53^{W T / W T}$ mice (10/10), and most untreated AlbuminCre; $p 53^{F L / F L}$ mice $(13 / 14)$ remained alive.

Non-tumour liver tissue from Albumin-Cre; $p 53^{F L / F L}$ mice retained the molecular features observed at the conclusion of the $\mathrm{CCl}_{4}$ treatment regime, including prominent hypertrophy in remaining normal hepatocytes (Fig. $4 \mathrm{~B}$ ) and significantly reduced CYP2A5 expression (Fig. 4B, E). Analysis of tumours from AlbuminCre; $p 53^{\text {WT WT }}$ mice (2 from mice at clinical endpoint and 2 small focal tumours identified at experiment endpoint) revealed that expression of CYP2A5 was elevated and MDA staining was low compared to tumours arising in Albumin-Cre; $p 53^{F L / F L}$ mice (Fig. 4C-E and Fig. S3C). These results confirmed that the disparate features of regeneration in Albumin-Cre; $p 53^{F L / F L}$ mice - namely elevated ROS, persistent liver damage, and decreased CYP2A5 expression-continued during tumourigenesis.
The p53-mediated expression of BBC3/PUMA has been shown to promote a pro-cancer metabolic switch in human HCC, correlating with poor prognosis in patients [46]. However, we did not observe differential expression of murine $B b c 3$ in endpoint $\mathrm{HCC}$ tumours arising in Albumin-Cre; $p 53^{W T / W T}$ mice after chronic $\mathrm{CCl}_{4}$ treatment compared with those in Albumin-Cre; p53 FL/FL mice (Fig. S3D). Expression of $C d k n 1 a / p 21$, in contrast, was elevated in the tumours of Albumin-Cre; $p 53^{W T / W T}$ mice (Fig. S3D). These findings suggest that in murine $\mathrm{HCC}$ arising from chronic $\mathrm{CCl}_{4}$ treatment the p53PUMA mediated metabolic switch [46] is not a defining feature of p53 WT HCC.

\section{CYP2A6 expression is prognostically favourable and clusters with a subset of p53-induced genes that correlate with increased survival in human HCC}

Given the strength of the association between increased survival, retention of $\mathrm{p} 53$, and expression of CYP2A5 in the murine $\mathrm{CCl}_{4}$ chronic regeneration model, we examined whether high expression of CYP2A6 correlated with increased survival in human HCC patients. Utilising the HCC dataset available through the cancergenome atlas (TCGA-LIHC dataset [59]), we confirmed that high expression of CYP2A6 was associated with significantly greater median survival in HCC (Fig. 4F). In addition, by stratifying the 
A

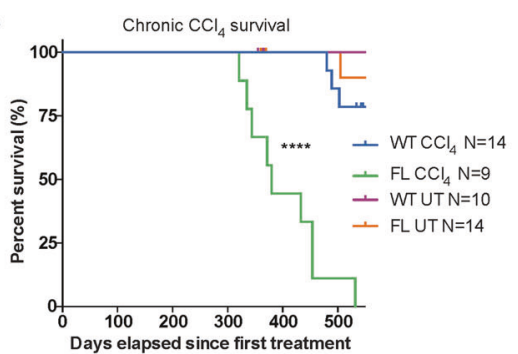

B

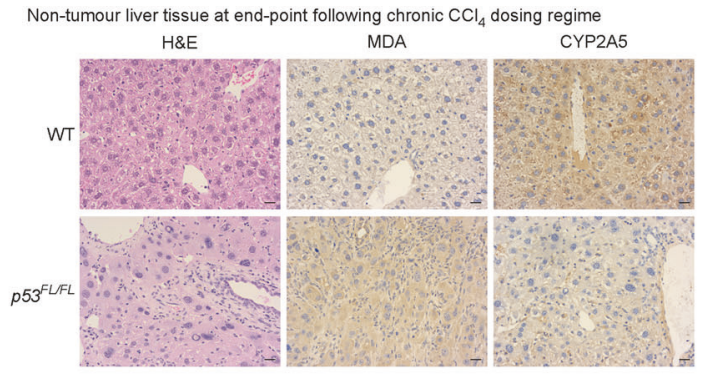

C

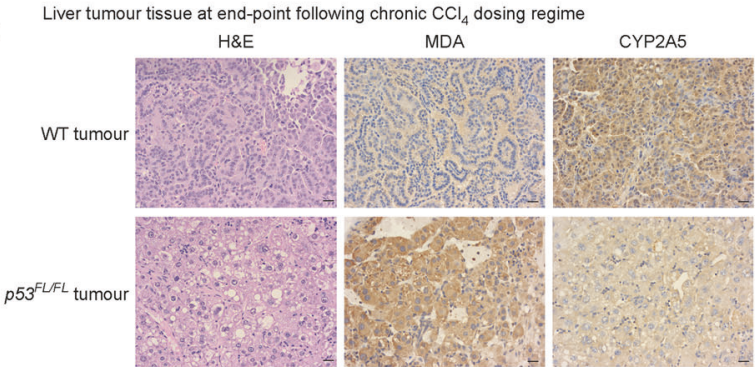

$\mathrm{F}$

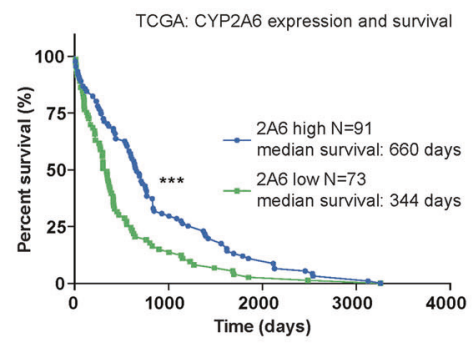

$\mathrm{H}$

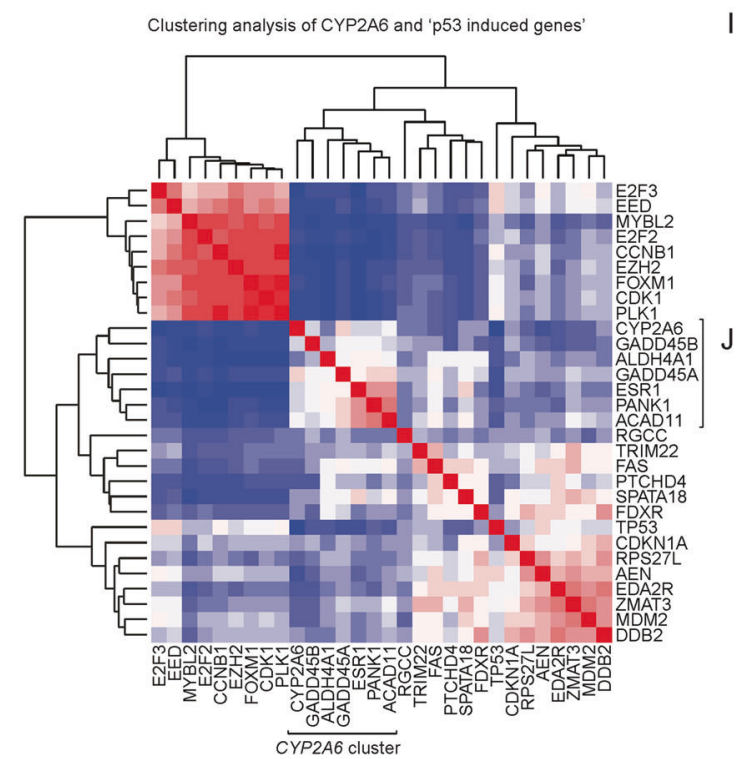

G
$\mathrm{D}$
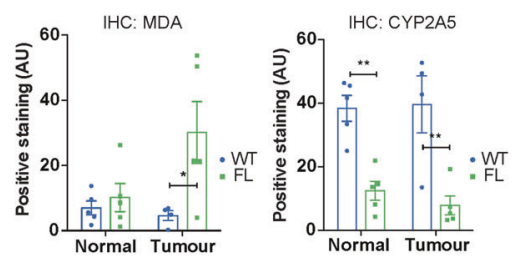
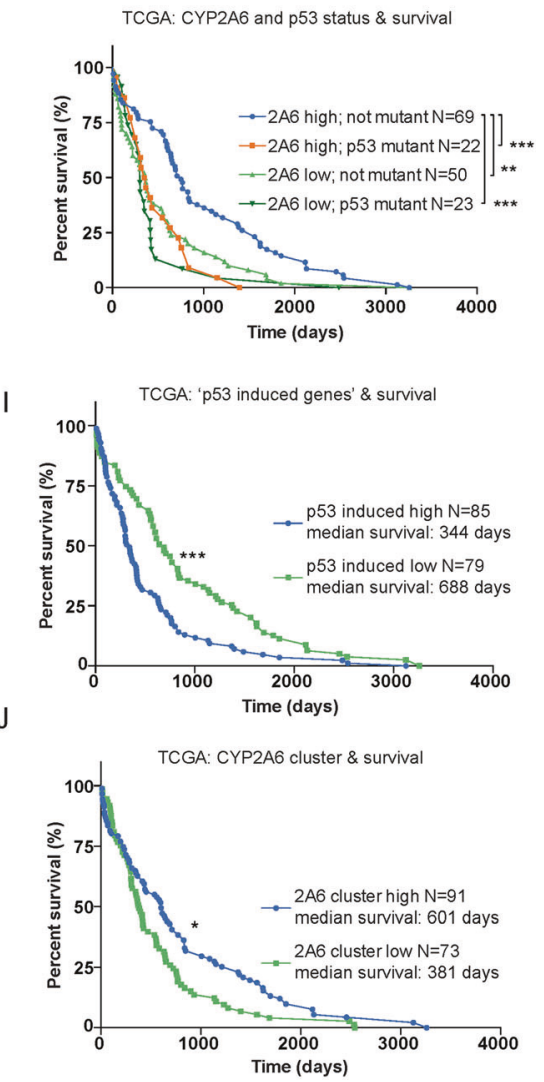

TCGA dataset between patients with disrupted TP53 (mutation or loss) and those with WT TP53, we further determined that high expression of CYP2A6 and retention of WT TP53 coincided with increased survival compared with all other combinations of tumours harbouring low expression of CYP2A6 and/or loss of WT TP53 (Fig. 4G).

Previous work utilising TCGA data has focused on the genomic determinants of human HCC [14]. In these analyses, the authors' identified a 'p53-induced gene target expression signature' as part of an aim to improve the clustering of HCC based on molecular and biological attributes [14]. Using the TCGA-LIHC dataset, we examined the relationship between these 20 identified p53-induced genes and 
Fig. 4 Liver p53 controls ROS, maintains expression of CYP2A5, and limits tumourigenesis following CCI4-mediated chronic regeneration. A Survival curve comparing Albumin-Cre; $p 53^{\text {WT/WT }}$ (WT) and Albumin-Cre; $p 53^{F L / F L}$ (FL) mice that were either untreated (UT) or administered the 10-week $\mathrm{CCl}_{4}$ chronic regeneration regime and aged until either reaching clinical endpoint or 550 days after initiation of treatment. Data presented as time (days) since initial $\mathrm{CCl}_{4}$ injection. $N=10 \mathrm{WT}$ and $N=14 \mathrm{FL}$ untreated mice, $N=14 \mathrm{WT}$ and $N=9 \mathrm{FL}$ chronic $\mathrm{CCl}_{4}$-treated mice. Of these, 0/10 WT and 1/14 FL UT mice and 3/14 WT and 9/9 FL CCl 4 -treated mice reached clinical endpoint within 550 days. All WT tumour mice (3/3) and the majority of FL endpoint tumour mice (5/9) exhibited focal tumour lesions along with substantial nontumour (normal-like) tissue. These regions were sampled as 'tumour' and 'non-tumour' tissue for subsequent analyses. Within these cohorts, $N$ $=4 \mathrm{WT}$ and $N=4 \mathrm{FL}$ untreated mice were examined at $\sim 365$ days and confirmed to be tumour free. Data analysed using Log-rank (Mantel-Cox) test. ${ }^{* * *} p<0.0001$. H\&E and IHC staining for MDA and CYP2A5 in non-tumour liver tissue (B) and tumour tissue (C) from Albumin-Cre; $p 53^{\text {WT/WT }}$ (WT) and Albumin-Cre; $p 53^{F / F L}\left(\mathrm{p} 53^{\mathrm{FL} / F \mathrm{~L}}\right.$ ) mice at clinical endpoint or 550 days post-treatment initiation after prior completion of 10-week $\mathrm{CCl}_{4}$ chronic regeneration regime. Scale bars $20 \mu \mathrm{m}$. Images representative of $N=5$ mice/group except $N=4$ WT tumours ( 2 from mice at clinical endpoint and 2 small focal tumours identified at experiment endpoint). Additional tumour images included in Supplemental Fig. 3B to illustrate staining from the diversity of tumours observed in the model. Quantification of IHC staining for MDA (D) and CYP2A5 (E) in Albumin-Cre; $p 53^{W T / W T}$ (WT) and Albumin-Cre; $p 53^{F L / F L}(\mathrm{FL})$ mice from (B/C). Data presented as mean \pm SEM and analysed using two-way ANOVA with Holm-Sidak's multiple comparisons test and multiplicity-adjusted $p$ values. ${ }^{*} p<0.05,{ }^{* *} p<0.01$. F Survival curve comparing HCC patients in the TCGA-LIHC dataset with high vs. low expression of CYP2A6 (2A6) on the basis of median survival. $N=91$ CYP2A6 high and $N=73$ CYP2A6 low patients. Data analysed using the Log-rank (Mantel-Cox) test. ${ }^{* *} p<0.001$. G Survival curve comparing HCC patients in the TCGA-LIHC dataset on the basis of TP53 status (loss or mutation of p53 (mutant) vs. WT TP53 (not mutant)) and further breakdown of high vs. low expression of CYP2A6 (2A6) on the basis of median survival. $N=692$ A6 high, not mutant, $N=222 A 6$ high, TP53 mutant, $N=502$ A6 low, not mutant, and $N=232$ A6 low, TP53 mutant. Data analysed using the Log-rank (Mantel-Cox) test. ${ }^{* *} p<0.01$, ${ }^{* * *} p<$ 0.001. H Clustering analysis of expression of CYP2A6 related to the previously identified 20 gene 'p53-Induced Gene Target Expression Signature' [14] using the TCGA-LIHC dataset. CYP2A6-associated cluster as indicated. For further information, see materials and methods. I Survival curve comparing HCC patients in the TCGA-LIHC dataset on the basis of high vs. low expression of the 'p53-Induced Gene Target Expression Signature' [14]. $N=85 / 79$ patients in the high and low groups. This analysis is independent of patient p53 status and includes all data in the TCGA-LIHC dataset. Data analysed using the Log-rank (Mantel-Cox) test. ${ }^{* *} p<0.001$. J Survival curve comparing HCC patients in the TCGA-LIHC on the basis of high vs. low expression of the subset of genes within the 'p53-Induced Gene Target Expression signature' that clustered with CYP2A6 expression in (H). $N=91 / 73$ patients in the high and low groups. Data analysed using the Log-rank (Mantel-Cox) test. ${ }^{*} p<0.05$.

CYP2A6 expression and found that CYP2A6 expression clustered with a subset of the p53-induced genes including GADD45B, ALDH4A1, GADD45A, ESR1, PANK1, and ACAD11 (Fig. 4H). Interestingly, although high expression of the full p53-induced gene target expression signature correlated with significantly reduced median survival in the TCGA-LIHC dataset (Fig. 4I), we found that high expression of the CYP2A6-associated gene cluster instead correlated with improved median survival (Fig. 4J). Taken together, these observations are consistent with a role for p53 and CYP2A6 in limiting liver cancer.

\section{DISCUSSION}

Tissue regeneration recapitulates many features of tumourigenesis, including potent activation of proliferative signalling pathways, changes to cellular metabolism, and rapid cell growth [60]. With this overlap in mind, we have examined the function of the canonical tumour suppressor protein p53 during regeneration. Using the liver as a model system, we have interrogated nontumour roles for p53 activity during both the acute and chronic responses to the liver toxin and carcinogen $\mathrm{CCl}_{4}$. We identified p53-mediated redox control and induction of CYP2A5/CYP2A6 as important features of the hepatic $\mathrm{p} 53$ response both in vivo and in human liver cancer cell lines in vitro.

Our findings suggest that a p53 programme is active during the priming phase of acute $\mathrm{CCl}_{4}$-mediated regeneration that includes induction of Cyp2a5, a cytochrome P450 enzyme that can be induced to control ROS in the liver $[42,43,61]$. In TP53 WT human HCC cell lines in vitro, we show that CYP2A6, the human orthologue to murine Cyp2a5, is similarly engaged in a p53dependent manner in response to $\mathrm{CCl}_{4}$ or Nutlin treatment, as well as in response to treatment with a ROS-inducing agent, cumene hydroperoxide. In treated cells, the loss of CYP2A6 exacerbates redox stress, confirming the role of CYP2A6 in supporting ROS control. Consistent with this observation, we show that p53 acts to limit the propagation of $\mathrm{CCl}_{4}$-mediated damage by controlling resulting ROS. These ROS-control activities, likely alongside additional functions of p53, promote rapid regeneration and restoration of normal liver function that is delayed in the absence of liver p53.
Our results are somewhat at odds with a previous report where Cyp2a5 was not shown to play a significant role in the hepatic response to $\mathrm{CCl}_{4}$ toxicity [62]. However, this study examined CYP2A5 activity only at $24 \mathrm{~h}$ after administration of a significantly smaller dose of $\mathrm{CCl}_{4}$ to initiate acute regeneration-leading to markedly less liver damage than observed in our model. This discrepancy raises the interesting possibility that p53 activation may require a threshold of liver damage, ROS, or other stimuli to be sufficiently engaged. Given that DNA damage occurs during $\mathrm{CCl}_{4}$ toxicity, the severity of induced DNA damage may play a role, and future work examining this prospect could clarify the activating signals that direct $\mathrm{p} 53$ during liver regeneration.

During the repeated damage of $\mathrm{CCl}_{4}$-mediated chronic liver regeneration, we found that the paradigms identified in acute regeneration persist. The presence of hepatic p53 does not limit, but rather leads to a slight increase in fibrosis in our model. Nevertheless, as in acute regeneration, p53 continues to engage CYP2A5, restrict lipid peroxidation, and maintain liver architecture and function. These protective actions are blunted in livers that lack p53, leading to pervasive hepatocyte hypertrophy, chronically increased ROS, unresolved DNA damage, and ultimately to mortality from liver cancer. Thus, in our system, increased fibrosis is not required for increased tumourigenesis. Further work is warranted to more carefully examine the relationship between fibrosis, p53 signalling, and liver tumourigenesis.

Our findings generalise to human HCC, where high expression of CYP2A6 correlates with increased median survival, as well as increased survival in the subset of patients that retain WT TP53 and maintain high expression of CYP2A6. These results suggest that increased CYP2A6 expression is an important component of p53's tumour-suppressive function. Even so, our results also suggest that elevated CYP2A6 alone is not sufficient to substitute for p53 activity in limiting liver tumorigenesis, consistent with the diverse repertoire of p53 tumour-suppressive activities in the cell. We have further distinguished a group of six genes previously reported as part of a p53-induced gene signature in human HCC [14] whose expression clusters with CYP2A6 and together account for improved median survival-in contrast with the poor prognosis associated with high expression of the entire gene set. 
Focusing on this point, we were surprised that high expression of the whole p53 gene signature significantly reduced median patient survival. However, it has been shown that p53 can help to protect cancer cells from nutrient starvation $[63,64]$, reduce cell death from ferroptosis [65, 66], and enhance redox control to limit ROS $[67,68]$. In addition, common tumour-derived p53 mutants have been found to retain aspects of WT p53 function that promote adaptation to metabolic stress $[69,70]$. With these findings in mind, and considering that 'pro-tumourigenic' p53 is an established paradigm in skin carcinogenesis [71-73], it is conceivable that aspects of p53 function can also enhance tumourigenesis in the liver. Future work investigating this possibility is warranted.

In humans, expression of CYP2A6 and of various CYP2A6 polymorphisms have been linked to higher rates pancreatic and colorectal cancer but to mostly reduced rates of lung and oesophageal cancer [74-78]. These findings suggest tissue, and potentially carcinogen-specific, functions for CYP2A6 in limiting or promoting tumourigenesis. In the liver, our findings suggest that expression of CYP2A6 is beneficial. One method to infer CYP2A6 activity non-invasively is through the analysis of CYP2A6-derived urinary metabolites of caffeine [74, 75]. Increased consumption of coffee reduces the risk of developing HCC [79]. As such, it would be interesting to examine whether caffeine consumption promotes CYP2A6 expression. If so, this pathway could account for some of the protective features of coffee consumption against HCC. Future work examining this relationship, as well as whether CYP2A6 activity in HCC patients has prognostic or stratification value, is warranted.

Taken together, our results underscore the importance of p53 for maintaining liver function following damage. Interestingly, in contrast to previous models showing that the tumour suppressor function of p53 is a reflection of its ability to drive the elimination of damaged cells [80], our work shows that the repair and survival activities of p53 can also suppress the development of HCC.

\section{MATERIALS AND METHODS \\ Mice}

Procedures involving mice were performed under Home Office licence numbers 70/8645, PP6345023, and 70/8891. Experiments were conducted in accordance with the Animals (Scientific Procedures) Act 1986 and the EU Directive 2010 and sanctioned by Local Ethical Review Process (University of Glasgow). Mice were housed on a 12-h light/12-h dark cycle and provided with normal chow diet and water ad libitum. Mice were genotyped by Transnetyx (Cordova, TN).

p5 $53^{\mathrm{FL} / \mathrm{FL}}\left(\operatorname{Trp} 53^{\mathrm{tm} 1 \mathrm{Brn}}\right)$, Albumin-Cre (Speer6-ps $1^{\mathrm{Tg}(\mathrm{Alb}-\mathrm{cre}) 21 \mathrm{Mgn})}$ ) and $M d m 2^{E \times 5 / 6 \Delta}\left(M^{2} 2^{\text {tm2.1Glo }}\right)$ mice were described previously [47, 81, 82].

For acute $\mathrm{CCl}_{4}$-mediated liver regeneration, mice were treated as previously described $[53,83]$. In brief, young male Albumin-Cre; $p 53^{\text {WTWT }}$ and Albumin-Cre; $p 53^{F L F L}$ mice (approx. 70 days old) were given $\mathrm{CCl}_{4}(1 \mathrm{~mL} / \mathrm{kg}$ from stock solution of $20 \% \mathrm{CCl}_{4} \mathrm{v} / \mathrm{v}$ in corn oil) (Sigma cat\# 289116 and C8267) via a single intraperitoneal (IP) injection administered in the morning. Mice receiving NACsupplemented drinking water were provided with $30 \mathrm{mM}$ NAC (Sigma cat\# A7250) in water ad libitum for $72 \mathrm{~h}$ prior to treatment with $\mathrm{CCl}_{4}$ and throughout the recovery period after treatment.

For chronic $\mathrm{CCl}_{4}$-mediated liver regeneration, young male Albumin-Cre; $p 53^{\text {WTWT }}$ and Albumin-Cre; $p 53^{\text {FLFL }}$ mice (approx. 70 days old) were treated weekly with IP injections of $\mathrm{CCl}_{4}\left(1 \mathrm{~mL} / \mathrm{kg}\right.$ from stock solution of $20 \% \mathrm{CCl}_{4} \mathrm{v} / \mathrm{v}$ in corn oil) for 10 consecutive weeks. Separate cohorts of mice were either sampled 7 days after the final injection or monitored until reaching clinical endpoint (or 550 days after the first injection) and sampled at this time.

Cohorts were composed of fully backcrossed C57BL/6J (N10) Albumin-Cre; $p 53^{W T W T}$ and Albumin-Cre; $p 53^{\text {FLFL }}$ male mice. Some mice from both genotypes also contained the Rosa26 $6^{\text {LLL-tdRFP }}$ (Gt(ROSA)26Sor ${ }^{\text {tm1 } 1 \mathrm{Hif}}$ ) reporter allele [84], which did not affect the response to $\mathrm{CCl}_{4}$ treatment. The experimental unit in all of our analyses was the individual mouse. No statistical test was performed to predetermine sample size. Initial pilot studies suggested a strong effect of liver $p 53$ status on the response to $\mathrm{CCl}_{4}$ treatment $24-72 \mathrm{~h}$ after administration, and subsequent experiments were performed using sample sizes based on standard protocols in the field. No animals were excluded from analysis. Within each experiment, mice were age and littermate matched as much as possible, and all treated at the same time. Downstream analyses were performed on a random order of samples blinded to the genotype and treatment regime until the summation of results.

For $M d m 2^{E \times 5 / 6 \Delta}$ RNA-seq experiments, mice homozygous for the $M d m 2^{\text {tm2.1Glo }}$ allele were bred on a mixed background. 8-12 week old male mice were injected with either AAV8.TBG.PI.Cre.rBG (Addgene, 107787-AAV8) or AAV8.TBG.PI.Null.bGH (Addgene, 105536-AAV8) at a dose of $2 \times 10^{11}$ genetic copies/mouse, as described previously [23]. Male mice of the same age and genotype, but without AAV injection, served as baseline controls (Untreated/uninduced controls). All mice were euthanized at $48 \mathrm{~h}$ post-AAV injection via $\mathrm{CO}_{2}$ inhalation.

\section{Recombination PCR}

For recombination PCR, liver DNA from Albumin-Cre; $p 53^{W T / W T}$ mice (WT) and liver and kidney DNA from Albumin-Cre; $p 53^{F L F L}\left(p 53^{F L / F L}\right)$ adult mice were isolated as previously described [85]. DNA was amplified using KOD Hot Start Master Mix (Merck Millipore cat\# 71842) according to standard protocols. PCR primers were previously described [86].

\section{Liver function assays (ALT/AST)}

ALT and AST activity were determined in EDTA-treated plasma using the Alanine Transaminase Activity Assay Kit (ab105134) and the Aspartate Aminotransferase Activity Assay Kit (ab138878) from Abcam. Both assays were performed following the manufacturer's recommendations. Samples were run together, analysed in duplicate wells per mouse sample, and the mean value of these technical replicates was used for subsequent analysis.

\section{Immunohistochemistry (IHC) and special staining}

Staining for oil-red-O was performed on $10 \mu \mathrm{m}$ frozen sections that were first fixed for $5 \mathrm{~min}$ in $10 \%$ neutral buffered formalin (Solmedia), rinsed in tap water, and then briefly rinsed in 60\% isopropanol (Fisher Chemicals). Slides were stained in freshly prepared and filtered oil-red-O staining solution $(0.5 \% \mathrm{w} / \mathrm{v}$ oil-red-o (Merck Life Science, UK) in isopropanol (Fisher Chemicals)) for $15 \mathrm{~min}$ with agitation. Slides were subsequently blotted, rinsed with $60 \%$ isopropanol and then water, before application of Mayers Haematoxylin (Sigma Aldrich) to stain the nuclei. Stained slides were first sealed using Aqueous mountant (Dako) and left overnight before being coverslipped using DPX mountant (CellPath, UK).

Staining for PSR was performed on $4 \mu \mathrm{m}$ formalin-fixed paraffinembedded sections that were de-waxed and rehydrated through xylene and a graded ethanol series. Rehydrated slides were stained for $2 \mathrm{~h}$ in PSR staining solution (equal volumes of $0.1 \%$ Direct red 80 (Sigma Aldrich) and $0.1 \%$ Fast green (Raymond A Lamb) (both in distilled water) combined in a 1:9 dilution with aqueous Picric acid solution (VWR)), rinsed in tap water, and dehydrated through a graded ethanol series and xylene before being coverslipped using DPX mountant (CellPath, UK).

Manual and automated IHC staining were performed as previously described $[69,85]$ with the reagents and staining platform used for each antibody as noted in the accompanying reagent and antibody information tables (Supplementary Tables 1 and 2).

\section{Analysis of IHC images}

The analysis of $\mathrm{IHC}$ staining in $\mathrm{CCl}_{4}$ experiments, and for CYP2A5 IHC staining in $M d m 2^{E \times 5 / 6 \Delta}$ mice, was performed as previously described [69, 85].

For the analysis of IHC staining for p53 and p21 in Mdm2 $2^{E \times 5 / 6 \Delta}$ mice, a Leica Aperio AT2 slide scanner (Leica Microsystems, UK) was used to scan stained sections at $20 \times$ magnification. Histological scoring was performed using HALO image analysis software (V3.1.1076.363, Indica Labs).

\section{Quantification of liver damage}

A minimum of five random non-overlapping $4 \times$ magnification fields were taken from each H\&E stained slide using an Olympus BX51 microscope with Zen Blue software (Zeiss). From these images, damage was manually traced and the total damaged area per slide was calculated using imageJ software.

\section{Cell culture}

HepG2 (HB-8065) and SK-Hep-1 (HTB-52) cells were obtained from ATCC but were not authenticated. Mycoplasma testing was performed when cells were thawed and semi-regularly thereafter using the MycoAlert Mycoplasma Detection Kit (Lonza LT07-318). Independent experiments were performed on cells treated with siRNA and compounds from separate 
passages of each cell line. Stock flasks were maintained in DMEM glucose, glutamine, and phenol red-free medium (Gibco, A1443001) supplemented with $4 \mathrm{mM}$ glucose (Sigma cat\# 49163), $1 \mathrm{mM}$ pyruvate (Gibco cat\# 11360088), 1 mM L-Glutamine (Gibco cat\# 25030032), penicillin/streptomycin (Gibco cat\# 15070063), Gentamycin (Gibco cat\# 15750037), and 10\% FBS (Gibco cat\# 10091148). Cells were cultured at $37^{\circ} \mathrm{C}$ in a humidified atmosphere of $5 \% \mathrm{CO}_{2}$.

Cells were treated with $10 \mu \mathrm{M}$ Nutlin-3a (Nutlin) (Sigma cat\# SML0580) dissolved in DMSO, $4 \mathrm{mM} \mathrm{CCl}_{4}$ (Sigma cat\# 289116) dissolved in DMSO, 10 $\mu \mathrm{M}$ cumene hydroperoxide (Thermo Fisher Scientific cat\# C10445) dissolved in DMSO, or DMSO as vehicle control. For in vitro experiments, $\mathrm{CCl}_{4}$ was prepared by first combining an $80 / 20(\mathrm{v} / \mathrm{v})$ mixture of $\mathrm{CCl}_{4}$ and DMSO with media to make a $100 \times$ stock. The stock was then sonicated for 5 min to disperse the $\mathrm{CCl}_{4}$ mixture and the resulting solution was added to cells.

\section{Transfection with siRNA}

Studies utilising siRNA knockdown were performed as previously described [69], with siGENOME SMARTpool siRNA constructs (Horizon) used for the non-targeting siRNA control pool (D-001206-13-05) and to target P53 (M003329-03-0005) and CYP2A6 (M-008781-02-0005). Constructs were used to transfect cell lines at $20 \mathrm{nM}$ concentration using the Lullaby siRNA transfection reagent and the manufacturer's recommended reverse transfection procedure (OZ Biosciences).

\section{Flow cytometry}

HepG2 and SK-Hep-1 cells were analysed for cellular ROS levels as previously described [69]. Data were analysed using FlowJo X 10.0.7r2 (FlowJo, LLC) and median fluorescence intensity values were obtained and compared across samples.

\section{RNA-seq}

Liver samples were isolated and preserved in Allprotect tissue reagent (Qiagen cat\# 76405) $\left(\mathrm{CCl}_{4}\right.$ samples) or snap frozen on dry ice and stored at $-80^{\circ} \mathrm{C}$ until RNA extraction ( $M d m 2^{E \times 5 / 6 \Delta}$ samples). To isolate RNA, tissue was homogenised using a Precellys tissue homogeniser (Bertin Instruments) and RNA was extracted using the RNeasy Plus Universal mini kit (Qiagen cat\# 73404) ( $\mathrm{CCl}_{4}$ samples) or the RNeasy mini kit (Qiagen cat\# 74104) (Mdm2 $2^{E \times 5 / 6 \Delta}$ samples), all according to the manufacturers' recommendations. The quality of the purified RNA was tested on an Agilent 2200 Tapestation using RNA screentape (Agilent). Libraries for cluster generation and DNA sequencing were prepared as previously described using an Illumina TruSeq Stranded mRNA LT Kit (CCl4 samples) or an Illumina TruSeq Stranded mRNA HT Kit (Mdm2 $2^{\text {Ex5/64 }}$ samples) [87]. The quality and quantity of the DNA libraries was assessed on an Agilent 2200 Tapestation (D1000 screentape) and Qubit (Thermo Fisher Scientific), respectively. The libraries were run on the Illumina Next Seq 500 using the High Output 75 cycles kit $(2 \times 36$ cycles, paired-end reads, single index for $\mathrm{CCl}_{4}$ samples and $2 \times 36$ cycles, paired-end reads, dual index for $M d m 2^{E \times 5 / 6 \Delta}$ samples).

\section{Analyses of RNA-seq expression data}

For $\mathrm{CCl}_{4}$ RNA-seq, Fastq files were generated from the sequencer output using Illumina's bcl2fastq (version 2.15.0.4) and quality checks on the raw data were done using FastQC (version 0.10.1) [88] and FastQ Screen (version 0.4.2) [89]. Alignment of the RNA-Seq paired-end reads was to the GRCh38.75 [90] version of the mouse genome and annotation using Tophat (version 2.0.13) with Bowtie (version 2.2.6.0) [91]. Expression levels were determined and statistically analysed by a workflow combining HTSeq (version 2.2.4.0) [92], the R environment (version 3.4.2) [93], and packages from the Bioconductor data analysis suite [94]. Differential gene expression analysis was based on the negative binomial distribution using the DESeq2 package [95]. "Heatmap.2" function of gplots package [96] was used for hierarchical clustering of significant hits.

For $M d m 2^{E \times 5 / 6 \Delta}$ RNA-seq, quality checks and trimming on the raw RNASeq data files were done using FastQC (version 0.11.7) [88], FastP [97] and FastQ Screen (version 0.12.0) [89]. RNA-Seq paired-end reads were aligned to the GRCh38.92 [90] version of the mouse genome and annotated using HiSat2 version 2.1.0 [98]. Expression levels were determined and statistically analysed by a combination of HTSeq version 0.9.1 [92] and the $\mathrm{R}$ environment version 3.4 [93], utilising packages from the Bioconductor data analysis suite [94] and differential gene expression analysis based on the negative binomial distribution using the DESeq2 package version 1.18.1 [95].

\section{TCGA analysis}

Survival, mutation and expression data were obtained via cBioPortal $[99,100]$. The results here are in whole or part based upon data generated by the TCGA Research Network (http://cancergenome.nih.gov/), using the TCGA-LIHC dataset [59].

The optimal cut-off point for high or low expression of CYP2A6 in survival analyses was determined using the "surv_cutpoint" function of survminer package in $R(0.4 .8)[93,101]$. Overall survival data from patients for each expression group was plotted and analysed using inbuilt tools as indicated in Prism 7 (Graph Pad). Correlations between CYP2A6 expression and the 'P53-induced gene target expression signature' [14] were assessed using the "cor" function from base R [93]. Then, the resulting heatmap was plotted using the function "corrplot" from the corrplot package (Version 0.84) to plot heatmaps [102].

\section{Quantitative RT-PCR}

For qPCR analysis of mouse tissue, liver samples were isolated and preserved in Allprotect tissue reagent (Qiagen cat\# 76405). RNA was extracted as previously described [85]. CDNA was synthesised using the high capacity RNA-to-cDNA kit (Thermo Fisher Scientific cat\# 4387406) and qPCR reactions were performed on a QuantStudio 5 real-time PCR system (Thermo Fisher Scientific) using Taqman FAST advanced master mix and Taqman gene expression assays (all Thermo Scientific) according to the manufacturer's recommendations and using the assays listed in Supplemental Table 3. Gene expression was quantified relative to the housekeeping gene Beta-glucuronidase according to the comparative $\Delta \Delta \mathrm{Ct}$ method.

For QPCR analysis of human cell lines, RNA was extracted from HepG2 and SK-Hep-1 cells using the RNeasy mini kit (Qiagen cat\# 74104) according to the manufacturer's recommendations, omitting the optional additional DNase treatment step. CDNA synthesis and qPCR reactions were performed as for mouse tissue samples described above. Gene expression in human cell lines was quantified relative to the housekeeping gene $A C T I N$ according to the comparative $\Delta \Delta C$ t method.

\section{Data plotting and statistical analysis}

Data were plotted using Prism 7 (Graph Pad). The statistical analysis for each experiment was performed using the test indicated in the relevant figure legend and multiplicity-adjusted $p$ values using the built-in analysis tools of Prism 7. Statistical tests were chosen based on the nature of the comparison being made and the corresponding standard tests utilised in the field. Underlying assumptions for these tests, including sample independence, variance equality, and normality were assumed to be met although not explicitly examined. Figures were prepared using Illustrator (Adobe). Unless otherwise indicated, data are represented as mean \pm standard error of the mean (SEM) for error bars. Asterisks denote $p$ value as follows: ${ }^{*} p<0.05,{ }^{* *} p<0.01$, ${ }^{* * *} p<0.001,{ }^{* * *} p<0.0001$.

\section{DATA AVAILABILITY}

The data that support the findings of this study are available from the corresponding authors upon reasonable request. RNA-seq data discussed in this paper have been deposited in NCBI's Gene Expression Omnibus and are accessible through GEO Series accession numbers GSE183053 and GSE183082.

\section{REFERENCES}

1. Levine AJ. p53: 800 million years of evolution and 40 years of discovery. Nat Rev Cancer. 2020;20:471-80. http://www.nature.com/articles/s41568-020-0262-1.

2. Hu W, Feng Z, Teresky AK, Levine AJ. p53 regulates maternal reproduction through LIF. Nature. 2007:450:721-4. http://www.nature.com/articles/nature05993.

3. Park J-Y, Wang $P$, Matsumoto $T$, Sung HJ, Ma W, Choi JW, et al. p53 Improves aerobic exercise capacity and augments skeletal muscle mitochondrial DNA content. Circ Res. 2009;105:705-12. https://www.ahajournals.org/doi/10.1161/ CIRCRESAHA.109.205310

4. Matoba S, Kang J-G, Patino WD, Wragg A, Boehm M, Gavrilova O, et al. P53 regulates mitochondrial respiration. Science. 2006;312:1650-3. http://www.ncbi. nlm.nih.gov/pubmed/16728594. 
5. Krizhanovsky V, Yon M, Dickins RA, Hearn S, Simon J, Miething C, et al. Senescence of activated stellate cells limits liver fibrosis. Cell. 2008;134:657-67. https://linkinghub.elsevier.com/retrieve/pii/S0092867408008362.

6. Wang S, Liu P, Wei J, Zhu Z, Shi Z, Shao D, et al. Tumor suppressor p53 protects mice against Listeria monocytogenes infection. Sci Rep. 2016;6:33815. http:// www.nature.com/articles/srep33815.

7. Montes de Oca Luna R, Wagner DS, Lozano G. Rescue of early embryonic lethality in mdm2-deficient mice by deletion of p53. Nature. 1995;378:203-6. http://www.ncbi.nlm.nih.gov/pubmed/7477326.

8. Jones SN, Roe AE, Donehower LA, Bradley A. Rescue of embryonic lethality in Mdm2-deficient mice by absence of p53. Nature. 1995;378:206-8. http://www. ncbi.nlm.nih.gov/pubmed/7477327.

9. Chavez-Reyes A, Parant JM, Amelse LL, de Oca Luna RM, Korsmeyer SJ, Lozano G. Switching mechanisms of cell death in mdm2- and mdm4-null mice by deletion of p53 downstream targets. Cancer Res. 2003;63:8664-9. http://www. ncbi.nlm.nih.gov/pubmed/14695178.

10. Tornovsky-Babeay S, Dadon D, Ziv O, Tzipilevich E, Kadosh T, Schyr-Ben Haroush R, et al. Type 2 diabetes and congenital hyperinsulinism cause DNA double-strand breaks and p53 activity in $\beta$ cells. Cell Metab. 2014;19:109-21. https://linkinghub. elsevier.com/retrieve/pii/S1550413113004567.

11. Pfaff MJ, Mukhopadhyay S, Hoofnagle M, Chabasse C, Sarkar R. Tumor suppressor protein p53 negatively regulates ischemia-induced angiogenesis and arteriogenesis. J Vasc Surg. 2018;68:222S-233S.e1. https://linkinghub.elsevier. com/retrieve/pii/S0741521418310267.

12. Hoshino A, Matoba S, Iwai-Kanai E, Nakamura $H$, Kimata $M$, Nakaoka $M$, et al. p53-TIGAR axis attenuates mitophagy to exacerbate cardiac damage after ischemia. J Mol Cell Cardiol. 2012;52:175-84. http://www.ncbi.nlm.nih.gov/ pubmed/22044588.

13. Vaseva AV, Marchenko ND, Ji K, Tsirka SE, Holzmann S, Moll UM. p53 Opens the mitochondrial permeability transition pore to trigger necrosis. Cell. 2012;149: 1536-48. https://linkinghub.elsevier.com/retrieve/pii/S0092867412005934.

14. The Cancer Genome Atlas Research Network. Comprehensive and integrative genomic characterization of hepatocellular carcinoma. Cell. 2017;169:1327-1341. e23. https://linkinghub.elsevier.com/retrieve/pii/S0092867417306396.

15. Katz S, Lechel A, Obenauf AC, Begus-Nahrmann Y, Kraus JM, Hoffmann EM, et al. Disruption of Trp53 in livers of mice induces formation of carcinomas with bilineal differentiation. Gastroenterology. 2012;142:1229-1239.e3. https:// linkinghub.elsevier.com/retrieve/pii/S0016508512002041.

16. Michalopoulos GK. Liver regeneration. J Cell Physiol. 2007;213:286-300. http:// doi.wiley.com/10.1002/jcp.21172.

17. Kurinna S, Stratton SA, Coban Z, Schumacher JM, Grompe M, Duncan AW, et al. p53 regulates a mitotic transcription program and determines ploidy in normal mouse liver. Hepatology. 2013;57:2004-13. http://doi.wiley.com/10.1002/ hep.26233.

18. Huo Y, Yin S, Yan M, Win S, Aung Than T, Aghajan M, et al. Protective role of p53 in acetaminophen hepatotoxicity. Free Radic Biol Med. 2017;106:111-7. https:// linkinghub.elsevier.com/retrieve/pii/S0891584917300898.

19. Borude P, Bhushan B, Gunewardena S, Akakpo J, Jaeschke H, Apte U. Pleiotropic role of p53 in injury and liver regeneration after acetaminophen overdose. Am J Pathol. 2018;188:1406-18. https://doi.org/10.1016/j.ajpath.2018.03.006.

20. Bellamy COC, Clarke AR, Wyllie AH, Harrison DJ. p53 deficiency in liver reduces local control of survival and proliferation, but does not affect apoptosis after DNA damage. FASEB J. 1997;11:591-9. https://onlinelibrary.wiley.com/doi/abs/ 10.1096/fasebj.11.7.9212083.

21. Buitrago-Molina LE, Marhenke $S$, Longerich $T$, Sharma AD, Boukouris $A E$, Geffers $\mathrm{R}$, et al. The degree of liver injury determines the role of p21 in liver regeneration and hepatocarcinogenesis in mice. Hepatology. 2013;58:1143-52. http:// doi.wiley.com/10.1002/hep.26412.

22. Marhenke S, Buitrago-Molina LE, Endig J, Orlik J, Schweitzer N, Klett S, et al. p21 promotes sustained liver regeneration and hepatocarcinogenesis in chronic cholestatic liver injury. Gut. 2014;63:1501-12. http://gut.bmj.com/lookup/doi/ 10.1136/gutjnl-2013-304829.

23. Bird TG, Müller M, Boulter L, Vincent DF, Ridgway RA, Lopez-Guadamillas E, et al. TGF $\beta$ inhibition restores a regenerative response in acute liver injury by suppressing paracrine senescence. Sci Transl Med. 2018;10:eaan1230. https://stm. sciencemag.org/lookup/doi/10.1126/scitranslmed.aan1230.

24. Lu W-Y, Bird TG, Boulter L, Tsuchiya A, Cole AM, Hay T, et al. Hepatic progenitor cells of biliary origin with liver repopulation capacity. Nat Cell Biol. 2015;17:971-83. http://www.nature.com/articles/ncb3203.

25. Farrell GC, Larter CZ, Hou JY, Zhang RH, Yeh MM, Williams J, et al. Apoptosis in experimental NASH is associated with p53 activation and TRAIL receptor expression. J Gastroenterol Hepatol. 2009;24:443-52. http://doi.wiley.com/ 10.1111/j.1440-1746.2009.05785.x.

26. Ferreira DMS, Afonso MB, Rodrigues PM, Simao AL, Pereira DM, Borralho PM, et al. c-Jun N-terminal kinase 1/c-Jun activation of the p53/MicroRNA 34a/
Sirtuin 1 pathway contributes to apoptosis induced by deoxycholic acid in rat liver. Mol Cell Biol. 2014;34:1100-20. http://mcb.asm.org/cgi/doi/ 10.1128/MCB.00420-13.

27. Tian X-F, Ji F-J, Zang H-L, Cao H. Activation of the miR-34a/SIRT1/p53 signaling pathway contributes to the progress of liver fibrosis via inducing apoptosis in hepatocytes but not in HSCs. PLoS ONE. 2016;11:e0158657. https://dx.plos.org/ 10.1371/journal.pone.0158657.

28. Tao $\mathrm{Y}$, Wang $\mathrm{M}$, Chen $\mathrm{E}$, Tang $\mathrm{H}$. Liver regeneration: analysis of the main relevant signaling molecules. Mediators Inflamm. 2017;2017.

29. Shteyer E, Liao Y, Muglia L, Hruz PW, Rudnick DA. Disruption of hepatic adipogenesis is associated with impaired liver regeneration in mice. Hepatology. 2004;40:1322-32. http://doi.wiley.com/10.1002/hep.20462.

30. Newberry EP, Kennedy SM, Xie Y, Luo J, Stanley SE, Semenkovich CF, et al. Altered hepatic triglyceride content after partial hepatectomy without impaired liver regeneration in multiple murine genetic models. Hepatology. 2008; 48:1097-105. http://doi.wiley.com/10.1002/hep.22473.

31. Weber LWD, Boll M, Stampfl A. Hepatotoxicity and mechanism of action of haloalkanes: carbon tetrachloride as a toxicological model. Crit Rev Toxicol. 2003;33:105-36. http://www.tandfonline.com/doi/full/10.1080/713611034.

32. Boll M, Weber LWD, Becker E, Stampfl A. Mechanism of carbon tetrachlorideinduced hepatotoxicity. Hepatocellular damage by reactive carbon tetrachloride metabolites. Z fur Naturforsch - Sect C J Biosci. 2001;56:649-59.

33. Long J, Wang X, Gao H, Liu Z, Liu C, Miao M, et al. Malonaldehyde acts as a mitochondrial toxin: Inhibitory effects on respiratory function and enzyme activities in isolated rat liver mitochondria. Life Sci. 2006;79:1466-72. https:// linkinghub.elsevier.com/retrieve/pii/S0024320506003377.

34. Chen Z, Tian R, She Z, Cai J, Li H. Role of oxidative stress in the pathogenesis of nonalcoholic fatty liver disease. Free Radic Biol Med. 2020;152:116-41. https:// linkinghub.elsevier.com/retrieve/pii/S0891584919315151.

35. Pessayre D. Role of mitochondria in non-alcoholic fatty liver disease. J Gastroenterol Hepatol. 2007;22:S20-7. http://doi.wiley.com/10.1111/j.1440-1746.2006.04640.x.

36. Eriksson SE, Ceder S, Bykov VJN, Wiman KG. p53 as a hub in cellular redox regulation and therapeutic target in cancer. J Mol Cell Biol. 2019;11:330-41. https://academic.oup.com/jmcb/article/11/4/330/5320090.

37. Lauterburg BH, Corcoran GB, Mitchell JR. Mechanism of action of $\mathrm{N}$-acetylcysteine in the protection against the hepatotoxicity of acetaminophen in Rats in vivo. J Clin Investig. 1983;71:980-91. http://www.jci.org/articles/view/ 110853.

38. Okamoto K, Beach D. Cyclin G is a transcriptional target of the p53 tumor suppressor protein. EMBO J. 1994;13:4816-22. http://www.ncbi.nlm.nih.gov/ pubmed/7957050.

39. Vilborg A, Bersani C, Wilhelm MT, Wiman KG. The p53 target Wig-1: a regulator of mRNA stability and stem cell fate? Cell Death Differ. 2011;18:1434-40. http:// www.nature.com/articles/cdd201120.

40. Brosh R, Sarig R, Natan EB, Molchadsky A, Madar S, Bornstein C, et al. p53dependent transcriptional regulation of EDA2R and its involvement in chemotherapy-induced hair loss. FEBS Lett. 2010;584:2473-7. http://doi.wiley. com/10.1016/j.febslet.2010.04.058.

41. Thottassery JV, Zambetti GP, Arimori K, Schuetz EG, Schuetz JD. p53-dependent regulation of MDR1 gene expression causes selective resistance to chemotherapeutic agents. Proc Natl Acad Sci. 1997;94:11037-42. http://www.pnas. org/cgi/doi/10.1073/pnas.94.20.11037.

42. Leung TM, Lu Y. Alcoholic liver disease: from CYP2E1 to CYP2A5. Curr Mol Pharmacol. 2017;10:172-8. http://www.eurekaselect.com/openurl/content.php? genre $=$ article \&issn $=1874-4672 \&$ volume $=10 \&$ issue $=3 \&$ spage $=172$.

43. Lu Y, Zhang XH, Cederbaum Al. Ethanol induction of CYP2A5: Role of CYP2E1ROS-Nrf2 pathway. Toxicol Sci. 2012;128:427-38. https://academic.oup.com/ toxsci/article/1649628/Ethanol.

44. Su T, Ding X. Regulation of the cytochrome P450 2A genes. Toxicol Appl Pharmacol. 2004;199:285-94. https://linkinghub.elsevier.com/retrieve/pii/S00 41008X04000626.

45. Hu H, Yu T, Arpiainen S, Lang MA, Hakkola J, Abu-Bakar A. Tumour suppressor protein p53 regulates the stress activated bilirubin oxidase cytochrome P450 2A6. Toxicol Appl Pharmacol. 2015;289:30-9. https://doi.org/10.1016/j. taap.2015.08.021.

46. Kim J, Yu L, Chen W, Xu Y, Wu M, Todorova $D$, et al. Wild-Type $p 53$ promotes cancer metabolic switch by inducing PUMA-dependent suppression of oxidative phosphorylation. Cancer Cell. 2019;35:191-203.e8. https://doi.org/10.1016/j. ccell.2018.12.012.

47. Grier JD, Yan W, Lozano G. Conditional allele of $\mathrm{mdm} 2$ which encodes a p53 inhibitor. genesis. 2002;32:145-7. https://onlinelibrary.wiley.com/doi/10.1002/ gene. 10066.

48. Yanger K, Knigin D, Zong Y, Maggs L, Gu G, Akiyama H, et al. Adult hepatocytes are generated by self-duplication rather than stem cell differentiation. Cell Stem Cell. 2014 Sep;15:340-9. https://linkinghub.elsevier.com/retrieve/pii/S1934590914002513. 
49. Vassilev LT, Vu BT, Graves B, Carvajal D, Podlaski F, Filipovic Z, et al. In vivo activation of the $\mathrm{p} 53$ pathway by small-molecule antagonists of MDM2. Science. 2004;303:844-8. http://www.ncbi.nlm.nih.gov/pubmed/14704432.

50. Vroegop SM, Decker DE, Buxser SE. Localization of damage induced by reactive oxygen species in cultured cells. Free Radic Biol Med. 1995;18:141-51. https:// linkinghub.elsevier.com/retrieve/pii/089158499400107U.

51. Rudraiah S, Gu X, Hines RN, Manautou JE. Oxidative stress-responsive transcription factor NRF2 is not indispensable for the human hepatic Flavin-containing monooxygenase-3 (FMO3) gene expression in HepG2 cells. Toxicol Vitr. 2016;31:54-9. https://linkinghub.elsevier.com/retrieve/pii/S0887233315300175.

52. Flier JS, Underhill LH, Dvorak HF. Tumors: wounds that do not heal. N Engl J Med. 1986;315:1650-9. http://www.nejm.org/doi/abs/10.1056/NEJM198612253152606.

53. Scholten D, Trebicka J, Liedtke C, Weiskirchen R. The carbon tetrachloride model in mice. Lab Anim. 2015;49:4-11. http://journals.sagepub.com/doi/10.1177/ 0023677215571192.

54. Bataller R, Brenner DA. Liver fibrosis. J Clin Investig. 2005;115:209-18. http:// www.jci.org/articles/view/24282.

55. Cichoż-Lach $\mathrm{H}$, Michalak A. Oxidative stress as a crucial factor in liver diseases. World J Gastroenterol. 2014;20:8082. http://www.wjgnet.com/1007-9327/full/ v20/i25/8082.htm

56. Richter K, Kietzmann T. Reactive oxygen species and fibrosis: further evidence of a significant liaison. Cell Tissue Res. 2016;365:591-605. http://link.springer.com/ 10.1007/s00441-016-2445-3.

57. Miyaoka Y, Ebato K, Kato H, Arakawa S, Shimizu S, Miyajima A. Hypertrophy and unconventional cell division of hepatocytes underlie liver regeneration. Curr Biol. 2012;22:1166-75. https://doi.org/10.1016/j.cub.2012.05.016.

58. Heindryckx F, Colle I, Van Vlierberghe H. Experimental mouse models for hepatocellular carcinoma research. Int J Exp Pathol. 2009;90:367-86. http://doi. wiley.com/10.1111/j.1365-2613.2009.00656.x.

59. Erickson BJ, Kirk S, Lee $Y$, Bathe $O$, Kearns $M$, Gerdes $C$, et al. Radiology data from the cancer genome atlas liver hepatocellular carcinoma [TCGA-LIHC] collection. The Cancer Imaging Archive; 2016.

60. Ratajczak MZ, Bujko K, Mack A, Kucia M, Ratajczak J. Cancer from the perspective of stem cells and misappropriated tissue regeneration mechanisms. Leukemia. 2018:32:2519-26. http://www.nature.com/articles/s41375-018-0294-7.

61. Zhou X, Zhuo X, Xie F, Kluetzman K, Shu Y-Z, Humphreys WG, et al. Role of CYP2A5 in the clearance of nicotine and cotinine: insights from studies on a Cyp2a5-null mouse model. J Pharmacol Exp Ther. 2010;332:578-87. http://jpet. aspetjournals.org/lookup/doi/10.1124/jpet.109.162610.

62. Hong F, Si C, Gao P, Cederbaum Al, Xiong H, Lu Y. The role of CYP2A5 in liver injury and fibrosis: chemical-specific difference. Naunyn Schmiedebergs Arch Pharmacol. 2016;389:33-43. http://link.springer.com/10.1007/s00210-015-1172-8.

63. Tajan M, Hock AKAK, Blagih J, Robertson NANA, Labuschagne CFCF, Kruiswijk F, et al. A role for $\mathrm{p} 53$ in the adaptation to glutamine starvation through the expression of SLC1A3. Cell Metab. 2018;28:721-36.

64. Maddocks ODK, Berkers CR, Mason SM, Zheng L, Blyth K, Gottlieb E, et al. Serine starvation induces stress and p53-dependent metabolic remodelling in cancer cells. Nature. 2013;493:542-6. http://www.ncbi.nlm.nih.gov/pubmed/23242140.

65. Tarangelo A, Magtanong L, Bieging-Rolett KT, Li Y, Ye J, Attardi LD, et al. p53 suppresses metabolic stress-induced ferroptosis in cancer cells. Cell Rep. 2018;22:569-75. https://linkinghub.elsevier.com/retrieve/pii/S2211124717319149.

66. Xie Y, Zhu S, Song X, Sun X, Fan Y, Liu J, et al. The tumor suppressor p53 limits ferroptosis by blocking DPP4 activity. Cell Rep. 2017;20:1692-704. http://www. ncbi.nlm.nih.gov/pubmed/28813679.

67. Suzuki S, Tanaka T, Poyurovsky MV, Nagano H, Mayama T, Ohkubo S, et al. Phosphate-activated glutaminase (GLS2), a p53-inducible regulator of glutamine metabolism and reactive oxygen species. Proc Natl Acad Sci USA. 2010;107:7461-6.

68. Bensaad K, Tsuruta A, Selak MA, Vidal MNC, Nakano K, Bartrons R, et al. TIGAR, a p53-inducible regulator of glycolysis and apoptosis. Cell. 2006;126:107-20. http://www.ncbi.nlm.nih.gov/pubmed/16839880.

69. Humpton TJ, Hock AK, Maddocks ODK, Vousden KH. p53-mediated adaptation to serine starvation is retained by a common tumour-derived mutant. Cancer Metab. 2018;6:18. http://www.ncbi.nlm.nih.gov/pubmed/30524726.

70. Tran TQ, Lowman XH, Reid MA, Pan M, Yang Y, Kong M. Tumor-associated mutant $\mathrm{p} 53$ promotes cancer cell survival upon glutamine deprivation through p21 induction. 2016;36:1991-2001. https://doi.org/10.1038/onc.2016.360.

71. Kemp CJ, Donehower LA, Bradley A, Balmain A. Reduction of p53 gene dosage does not increase initiation or promotion but enhances malignant progression of chemically induced skin tumors. Cell. 1993;74:813-22. https://linkinghub. elsevier.com/retrieve/pii/009286749390461X.

72. Greenhalgh DA, Wang XJ, Donehower LA, Roop DR. Paradoxical tumor inhibitory effect of p53 loss in transgenic mice expressing epidermal-targeted v-rasHa, vfos, or human transforming growth factor alpha. Cancer Res. 1996 ;56:4413-23. http://www.ncbi.nlm.nih.gov/pubmed/8813135.
73. Kelly-Spratt KS, Gurley KE, Yasui Y, Kemp CJ. p19 Arf suppresses growth, progression, and metastasis of Hras-driven carcinomas through p53-dependent and -independent pathways. PLoS Biol. 2004;2:e242. https://dx.plos.org/ 10.1371/journal.pbio.0020242.

74. Kadlubar S, Anderson JP, Sweeney C, Gross MD, Lang NP, Kadlubar FF, et al. Phenotypic CYP2A6 variation and the risk of pancreatic cancer. JOP. 2009;10:263-70. http://www.ncbi.nlm.nih.gov/pubmed/19454817.

75. Nowell S, Sweeney C, Hammons G, Kadlubar FF, Lang NP. CYP2A6 activity determined by caffeine phenotyping: association with colorectal cancer risk. Cancer Epidemiol Biomarkers Prev. 2002;11:377-83. http://www.ncbi.nlm.nih. gov/pubmed/11927498.

76. Ariyoshi N, Miyamoto M, Umetsu Y, Kunitoh H, Dosaka-Akita H, Sawamura Y-I, et al. Genetic polymorphism of CYP2A6 gene and tobacco-induced lung cancer risk in male smokers. Cancer Epidemiol Biomarkers Prev. 2002;11:890-4. http:// www.ncbi.nlm.nih.gov/pubmed/12223434.

77. Tan W, Chen GF, Xing DY, Song CY, Kadlubar FF, Lin DX. Frequency of CYP2A6 gene deletion and its relation to risk of lung and esophageal cancer in the Chinese population. Int J Cancer. 2001;95:96-101. http://www.ncbi.nlm.nih.gov/ pubmed/11241319.

78. Wang H, Tan W, Hao B, Miao X, Zhou G, He F, et al. Substantial reduction in risk of lung adenocarcinoma associated with genetic polymorphism in CYP2A13, the most active cytochrome P450 for the metabolic activation of tobacco-specific carcinogen NNK. Cancer Res. 2003;63:8057-61. http://www.ncbi.nlm.nih.gov/ pubmed/14633739.

79. Kennedy OJ, Roderick P, Buchanan R, Fallowfield JA, Hayes PC, Parkes J. Coffee, including caffeinated and decaffeinated coffee, and the risk of hepatocellular carcinoma: a systematic review and dose-response meta-analysis. BMJ Open. 2017;7:e013739. https://bmjopen.bmj.com/lookup/doi/10.1136/bmjopen-2016013739.

80. Dhar D, Antonucci L, Nakagawa H, Kim JY, Glitzner E, Caruso S, et al. Liver cancer initiation requires $\mathrm{p} 53$ inhibition by $\mathrm{CD} 44$-enhanced growth factor signaling. Cancer Cell. 2018 Jun;33:1061-1077.e6. https://linkinghub.elsevier.com/retrieve/ pii/S1535610818302174.

81. Postic C, Shiota M, Niswender KD, Jetton TL, Chen Y, Moates JM, et al. Dual roles for glucokinase in glucose homeostasis as determined by liver and pancreatic $\beta$ cell-specific gene knock-outs using cre recombinase. J Biol Chem. 1999:274:305-15. http://www.jbc.org/lookup/doi/10.1074/jbc.274.1.305.

82. Marino S, Vooijs M, van Der Gulden H, Jonkers J, Berns A. Induction of medulloblastomas in p53-null mutant mice by somatic inactivation of $\mathrm{Rb}$ in the external granular layer cells of the cerebellum. Genes Dev. 2000;14:994-1004. http://www.ncbi.nlm.nih.gov/pubmed/10783170.

83. Zhu R, Zeng G, Chen Y, Zhang Q, Liu B, Liu J, et al. Oroxylin A accelerates liver regeneration in CCl4-induced acute liver injury mice. PLoS ONE. 2013;8:e71612. https://dx.plos.org/10.1371/journal.pone.0071612.

84. Luche H, Weber O, Nageswara Rao T, Blum C, Fehling HJ. Faithful activation of an extra-bright red fluorescent protein in "knock-in" Cre-reporter mice ideally suited for lineage tracing studies. Eur J Immunol. 2007;37:43-53. http://www. ncbi.nlm.nih.gov/pubmed/17171761.

85. Humpton TJ, Nomura K, Weber J, Magnussen HM, Hock AK, Nixon C, et al. Differential requirements for MDM2 E3 activity during embryogenesis and in adult mice. Genes Dev. 2021;35:117-32. http://genesdev.cshlp.org/lookup/doi/ 10.1101/gad.341875.120.

86. Jonkers J, Meuwissen $R$, Van der Gulden $H$, Peterse $H$, Van der Valk $M$, Berns $A$ Synergistic tumor suppressor activity of BRCA2 and p53 in a conditional mouse model for breast cancer. Nat Genet. 2001;29:418-25.

87. Fisher S, Barry A, Abreu J, Minie B, Nolan J, Delorey TM, et al. A scalable, fully automated process for construction of sequence-ready human exome targeted capture libraries. Genome Biol. 2011;12:R1. http://genomebiology. biomedcentral.com/articles/10.1186/gb-2011-12-1-r1.

88. Andrews S. FastQC: a quality control tool for high throughput sequence data. 2018. http://www.bioinformatics.bbsrc.ac.uk/projects/fastqc.

89. Wingett S. FastQ Screen. 2018. http://www.bioinformatics.babraham.ac.uk/ projects/fastq_screen/.

90. Zerbino DR, Achuthan P, Akanni W, Amode MR, Barrell D, Bhai J, et al. Ensembl 2018. Nucleic Acids Res. 2018 46:D754-61. http://academic.oup.com/nar/article/ 46/D1/D754/4634002.

91. Trapnell C, Pachter L, Salzberg SL. TopHat: discovering splice junctions with RNASeq. Bioinformatics. 2009;25:1105-11. https://academic.oup.com/bioinformatics/ article-lookup/doi/10.1093/bioinformatics/btp120.

92. Anders S, Pyl PT, Huber W. HTSeq--a Python framework to work with highthroughput sequencing data. Bioinformatics. 2015;31:166-9. https://academic. oup.com/bioinformatics/article-lookup/doi/10.1093/bioinformatics/btu638.

93. R Core Team. R: a language and environment for statistical computing. Vienna: $\mathrm{R}$ Foundation for Statistical Computing; 2018. https://www.r-project.org/. 
94. Huber W, Carey VJ, Gentleman R, Anders S, Carlson M, Carvalho BS, et al. Orchestrating high-throughput genomic analysis with Bioconductor. Nat Methods. 2015;12:115-21. http://www.nature.com/articles/nmeth.3252.

95. Love Ml, Huber W, Anders S. Moderated estimation of fold change and dispersion for RNA-seq data with DESeq2. Genome Biol. 2014;15:550. http:// genomebiology.biomedcentral.com/articles/10.1186/s13059-014-0550-8.

96. Warnes GR, Bolker B, Bonebakker L, Gentleman R, Huber W, Liaw A, et al. gplots: various $\mathrm{R}$ programming tools for plotting data. $\mathrm{R}$ package version 3.1.0. 2020. https://cran.r-project.org/package=gplots.

97. Chen S, Zhou Y, Chen Y, Gu J. fastp: an ultra-fast all-in-one FASTQ preprocessor. Bioinformatics. 2018;34:i884-90. https://academic.oup.com/bioinformatics/ article/34/17/i884/5093234.

98. Kim D, Langmead B, Salzberg SL. HISAT: a fast spliced aligner with low memory requirements. Nat Methods. 2015;12:357-60. http://www.nature.com/articles/ nmeth.3317.

99. Cerami E, Gao J, Dogrusoz U, Gross BE, Sumer SO, Aksoy BA, et al. The cBio Cancer genomics portal: an open platform for exploring multidimensional cancer genomics data: Fig. 1. Cancer Discov. 2012;2:401-4. http:// cancerdiscovery.aacrjournals.org/lookup/doi/10.1158/2159-8290.CD-12-0095.

100. Gao J, Aksoy BA, Dogrusoz U, Dresdner G, Gross B, Sumer SO, et al. Integrative analysis of complex cancer genomics and clinical profiles using the cBioPortal. Sci Signal. 2013;6:pl1-pl1. https://stke.sciencemag.org/lookup/doi/10.1126/ scisignal.2004088.

101. Kassambara A, Kosinski M, Biecek P. Drawing survival curves using 'ggplot2'. 2020. http://www.sthda.com/english/rpkgs/survminer/.

102. Wei T, Simko V. R package "corrplot": visualization of a correlation matrix. 2017. https://github.com/taiyun/corrplot.

\section{ACKNOWLEDGEMENTS}

We would like to thank the Core Facilities and Advanced Technologies at the CRUK Beatson Institute, in particular the animal facilities staff, the histology team, the Molecular Technologies group, and the Bioinformatics services. We thank Catherine Winchester for comments on the manuscript.

\section{AUTHOR CONTRIBUTIONS}

TJH and KHV conceived and designed the project. $\mathrm{HH}$ analysed the RNA-seq data and liver TCGA-LIHC data. CK performed experiments with $M d m 2^{E \times 5 / 6 \Delta}$ mice, for which funding was provided by TGB. CN performed IHC. WC performed RNA sequencing. $\mathrm{AH}$ and RS analysed RNA-seq data. TJH performed all other experiments and data analysis with assistance from $\mathrm{HH}$. The work was supervised by TGB, KB and KHV. TJH and KHV wrote the manuscript and all authors discussed the results and revised and approved the manuscript prior to submission.

\section{FUNDING}

This work was funded by Cancer Research UK grant C596/A26855 and supported by The Francis Crick Institute which receives its core funding from Cancer Research UK (FC001557), the United Kingdom Medical Research Council (FC001557), and the Wellcome Trust (FC001557), and the CRUK Beatson Institute which receives its core funding from Cancer Research UK grant C596/A17196. HH was funded by BBSRC grant BB/N017005/2. Additional funding for the work was provided by Cancer Research UK grant A29799 (KB). TGB was funded by the Wellcome Trust (Grant number: WT107492Z) and CRUK HUNTER Accelerator Award (Grant number: A26813).

\section{COMPETING INTERESTS}

$\mathrm{KHV}$ is on the board of directors and a shareholder of Bristol Myers Squibb, and on the science advisory board (with stock options) of PMV Pharma, RAZE Therapeutics and Volastra Therapeutics, Inc. She is also on the SAB of Ludwig Cancer Research. $\mathrm{KHV}$ is a co-founder and consultant of Faeth Therapeutics. She has been in receipt of research funding from Astex Pharmaceuticals and AstraZeneca and contributed to CRUK Cancer Research Technology filing of Patent Application WO/2017/144877. TGB is in receipt of research funding from AstraZeneca.

\section{ETHICAL APPROVAL}

Procedures involving mice were performed under Home Office licence numbers 70/ 8645, PP6345023, and 70/8891. Experiments were conducted in accordance with the Animals (Scientific Procedures) Act 1986 and the EU Directive 2010 and sanctioned by Local Ethical Review Process (University of Glasgow). No human samples were used in this study.

\section{ADDITIONAL INFORMATION}

Supplementary information The online version contains supplementary material available at https://doi.org/10.1038/s41418-021-00871-3.

Correspondence and requests for materials should be addressed to Timothy J. Humpton or Karen H. Vousden.

Reprints and permission information is available at http://www.nature.com/ reprints

Publisher's note Springer Nature remains neutral with regard to jurisdictional claims in published maps and institutional affiliations.

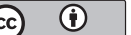

Open Access This article is licensed under a Creative Commons Attribution 4.0 International License, which permits use, sharing, adaptation, distribution and reproduction in any medium or format, as long as you give appropriate credit to the original author(s) and the source, provide a link to the Creative Commons license, and indicate if changes were made. The images or other third party material in this article are included in the article's Creative Commons license, unless indicated otherwise in a credit line to the material. If material is not included in the article's Creative Commons license and your intended use is not permitted by statutory regulation or exceeds the permitted use, you will need to obtain permission directly from the copyright holder. To view a copy of this license, visit http://creativecommons. org/licenses/by/4.0/.

(c) The Author(s) 2021 